\title{
Biochemical and Physicochemical Background of Mammalian Androgen Activity in Winter Wheat Exposed to Low Temperature
}

\author{
Anna Janeczko ${ }^{1} \cdot$ Jolanta Biesaga-Kościelniak $^{1} \cdot$ Michał Dziurka $^{1}$ Maria Filek $^{2}$ • \\ Katarzyna Hura ${ }^{3}$ - Barbara Jurczyk ${ }^{3}$ - Monika Kula ${ }^{1}$ - Jana Oklestkova ${ }^{4}$. \\ Ondrej Novak $^{4}$ Elżbieta Rudolphi-Skórska ${ }^{2}$ Andrzej Skoczowski ${ }^{1}$
}

Received: 23 February 2017 / Accepted: 17 May 2017 / Published online: 3 June 2017

(C) The Author(s) 2017. This article is an open access publication

\begin{abstract}
Understanding of the physiological role of mammalian hormone-androstenedione (AN) - in plants is scant and the mechanisms of its action at a cellular level are practically unknown. The aim of this study was to investigate the physicochemical and biochemical background of AN activity in winter wheat exposed to low temperature. Cold periods are important in the lifecycle of this species as they induce frost resistance and further generative development. Wheat seedlings (control and AN-supplemented) were acclimated 2 weeks in cold and then exposed to frost $\left(-12{ }^{\circ} \mathrm{C}\right)$. AN supplementation reduced frost damages by $30 \%$. Moreover, AN also accelerated generative
\end{abstract}

Electronic supplementary material The online version of this article (doi:10.1007/s00344-017-9719-1) contains supplementary material, which is available to authorized users.

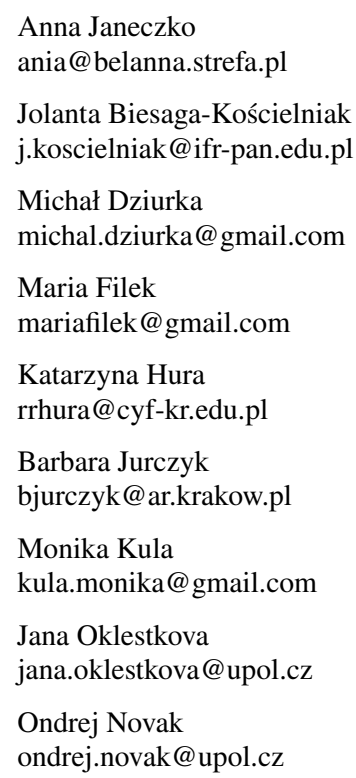

development of wheat. The AN-induced changes in redox homeostasis seemed to be important for processes of acclimation to low temperature and generative induction. AN influenced hormonal balance in wheat and stimulated accumulation among other gibberellins and cytokinins. For example, in aerial part of plants, the content of $\mathrm{GA}_{3}$ was increased by AN in 12 days of cold by about $30 \%$, whereas the content of cis-zeatin was increased by $65 \%$. AN was absorbed into plant membranes (Langmuir bath studies). The membrane absorption of AN increased the distance between lipid molecules and this may be an important step in the AN-induced enhancement of frost resistance. AN interaction with lipid membranes showed similarity to the interactions of some known regulators stimulating flowering in plants, and thus it may also underlie the acceleration

Elżbieta Rudolphi-Skórska erudolphi@tlen.pl

Andrzej Skoczowski amskoczowski@gmail.com

1 Polish Academy of Sciences, The Franciszek Górski Institute of Plant Physiology, Niezapominajek 21, 30-239 Krakow, Poland

2 Institute of Biology, Pedagogical University, Podchorażych 2, 30-084 Krakow, Poland

3 Department of Plant Physiology, University of Agriculture in Krakow, Podłużna 3, 30-239 Krakow, Poland

4 Laboratory of Growth Regulators, Centre of the Region Haná for Biotechnological and Agricultural Research, Institute of Experimental Botany ASCR and Palacký University, Šlechtitelů 27, 78371 Olomouc, Czech Republic 
of wheat development. Androstenedione was naturally present in wheat leaves (5-21 $\left.\mathrm{pg} \mathrm{g}^{-1} \mathrm{FW}\right)$.

Keywords Androstenedione $\cdot$ Frost resistance $\cdot$ Langmuir analysis $\cdot$ Phytohormones $\cdot$ Soluble sugars $\cdot$ Winter wheat

\section{Introduction}

Cultivars of winter plants have generally improved productivity and yield quality and hence they successfully compete with spring cultivars. Given the agronomic importance of winter plants, it is important to elucidate the mechanisms of their generative induction which occurs during the cold (vernalization process). They are also an important subject for studying the mechanism of plant acclimation to freezing temperatures because they survive in winter. The temperature required for inducing generative development (vernalization) is between 1 and $6^{\circ} \mathrm{C}$. The same temperature range has a hardening effect and allows for plant acclimation to subsequent winter frost. These two overlapping processes have been studied for decades (Scarth and Levitt 1937; Lang 1952), but new mechanisms and new components involved in the response of plants to cold are still being uncovered. Research into the mechanisms of plant acclimation to cold and subsequently plant tolerance to frost is crucial to agriculture. The results are useful for breeders to obtain varieties with better frost resistance. On the other hand, knowledge of the regulators that control the process of cold acclimation helps create agrochemicals useful for improving frost tolerance in crop plants.

Plant damage caused by frost is mainly due to freezing of water in the cells and dehydration processes (Beck and others 2004). This causes the destruction of biomembranes and the degree of membrane damage is manifested by electrolyte leakage from the cells. For this reason, in the cold, during the acclimation/hardening process, metabolic changes occur to prevent this happening. Plants respond to cold among other things with elevated level of sucrose and other osmoprotectants to increase the concentration of cell sap and lower its freezing point (Sasaki and others 1996); increase concentration of stress hormones [that is, abscisic acid (ABA)] engaging in adjustment of cell water management (Gusta and others 2005); increase the level of specific proteins-chaperones that protect the structure of other more susceptible proteins against dehydration damage (Kovacs and others 2008); changes in redox homeostasis-increase in enzymatic and non-enzymatic antioxidants (Boldizsár and others 2011; Awasthi and others 2015). Finally, one very important phenomenon is an increase, observed during the cold, of unsaturation of the fatty acids in membrane lipids (Skoczowski and Filek 1994) resulting in the reduction of the phase transition temperature and increase in the "fluidity" of the hydrophobic phase. This prevents accumulation of water in the membranes which during the thawing process can cause irreversible mechanical disruption. However, changes in lipids (hydrophilic-hydrophobic composition) also accompany the developmental processes in winter plants as well as changes in osmoprotectants and substances providing antioxidant and hormonal conditions (Filek and others 2007). Hence it is difficult to separate the biochemical effects associated with the adaptation of winter plant cells to lowtemperature stress and those that are directly associated with the induction of generative development. However, increased expression of 'vernalization genes'-TaVRNI, TaVRN2, or TaFT1 -in the meristem after cold treatment can be used to trace the effect of cold on generative induction in wheat (Diallo and others 2012). Among hormones whose concentrations change due to cold (in connection to plant generative development), are cytokinins (CKs) and gibberellins (GAs). CKs and GAs were postulated by the hormone theory of generative development induction due to Melchers (1939). This theory assumed the participation of the so-called "vernalins" (flowering hormone/hormones) that could be transmitted between organs to initiate plant generative development. "Vernalin" theory was supported by grafting experiments describing the diffusion of various substances (such as hormones) from the generative organs to the apical portions of non-vernalized plants which were connected with generative induction of non-vernalized plants (Filek and others 2003). The importance of GAs in the control of flowering in various plants is well established (Silverstone and others 1997; Bernier and Périlleux 2005; King and others 2006). The GA biosynthetic GAl gene is expressed in the expanded leaves and meristem apexes before the transition to flowering. As for CKs, their exogenous applications promoted flowering in Arabidopsis (Werner and others 2003). In transgenic plants, CK-deficiency blocked generative induction, and plants remained vegetative during the entire developmental period (Werner and others 2003). In Brassica winter plants, higher CK levels were observed in the later period of cold treatment that induces flowering (Tarkowska and others 2012).

Mentioned hormones-ABA, CKs, and GAs-belong to the so-called 'classic five,' along with auxins and ethylene. Their physiological activity is relatively well known. In recent years, the group has been extended to include jasmonic acid, polyamines, salicylic acid, and brassinosteroids (BRs), whose physiological properties are currently still being investigated. The list of regulators/hormones certainly is not closed (Davies 2010). BRs are so far the only recognized group of plant hormones with the structure and properties of steroids. BRs stimulate cell division and plant growth as well as increase plant tolerance to stress (Khripach and others 2000). Besides brassinosteroids in plants, 
there are also trace amounts of other steroids: steroid hormones of insects (ecdysteroids; Adler and Grebenok 1999) and mammalian sex hormones (progesterone, estrogens, androgens; Janeczko and Skoczowski 2005; Janeczko and others 2013). These compounds at the current stage of knowledge are not considered as plant hormones and relatively little is known about their role in plants. An example of such compounds is 4-androstene-3,17-dione (AN). In mammals (including humans), AN has weak androgenic properties and is an intermediate in the biosynthesis of testosterone and estrogens (Kley and others 1980; Milewich and Whisenant 1982). In plants, AN has been found in Nicotiana tabacum L. (7.69 $\mathrm{pmol} \mathrm{g}^{-1}$ of fresh weight) and Inula helenium L. (11.18 pmol g ${ }^{-1}$ of fresh weight) (Simerský and others 2009). Janeczko and Filek (2002) as well as Janeczko and others (2003) observed that application of AN stimulated flowering of Arabidopsis thaliana L. and winter wheat plants and improved stress resistance of soybean (Janeczko and others 2012), which suggests the possibility of participation of this substance in the processes supporting cold acclimation. However, the detailed mechanisms underlying the action of AN as a stimulator of generative development as well as a protective agent against low-temperature stress remain unexplained.

The aim of this study was to investigate

1. whether $\mathrm{AN}$ is found endogenously in winter wheat cells and if its content is dependent on the plant growth temperature;

2. whether exogenous AN may protect plants against lowtemperature stress and/or act as a flowering stimulator;

3. the activation of which antioxidant, hormonal, and/or osmoprotective (sugars) substances is dependent on AN treatment; and

4. whether AN can interact with cell membranes (due to its chemical similarity to sterols); whether this interaction is related to the hydrophilic or hydrophobic part of lipids and how it modifies membrane properties.

\section{Materials and Methods}

\section{Plant Material}

The study was conducted on the winter wheat (Triticum aestivum L.) cultivar Kobiera derived from "Nasiona Kobierzyce" (Kobierzyce, Poland) and whose vernalization demands have been previously established. In controlled greenhouse conditions, the normal generative development of this cultivar occurs after vernalization at $5{ }^{\circ} \mathrm{C}$ (cold) for approximately 6 weeks. According to the Development of Polish Official Variety Testing, cv. Kobiera is characterized by a high frost resistance.

\section{Experimental Design}

Three experiments investigating the role and mechanisms of action of androstenedione in wheat exposed to low temperature were conducted. Experiment 1 was dedicated to studying the impact of AN on wheat frost resistance. Simultaneously, we monitored the AN-induced biochemical changes (hormones, antioxidants, and sugars) during acclimation to cold (hardening process). The presence of endogenous $\mathrm{AN}$ in wheat and its changes during 2 weeks of cold were studied in experiment 1 . The second experiment was designed to show the stimulative effect of AN applied during cold (vernalization process) on the generative development of the wheat. The third experiment attempted to obtain an answer to the question of whether and how androstenedione can change the physicochemical properties of wheat cell membranes. Membranes are an important element in the mechanisms of cell response to low temperature.

\section{Design of Experiment 1 and Sampling}

The seeds were germinated on Petri dishes ( 2 days, darkness, $24^{\circ} \mathrm{C}$ ) and then they were moved into 12 new vessels $(10 \times 13 \times 2 \mathrm{~cm}, 40$ seeds per vessel). The vessels were kept in the greenhouse at a temperature of $20^{\circ} \mathrm{C}$ day/night, under natural solar radiation (April, latitude: $50^{\circ} 30^{\prime}$ North, longitude: $19^{\circ} 55^{\prime}$ East). Seeds in 6 vessels were watered with distilled water $50 \mathrm{~cm}^{3} / \mathrm{vessel}$ (control group). The plants in the remaining 6 vessels were watered with the same volume of AN aqueous solution ( $1 \mu \mathrm{M}$ concentration), prepared from the stock solution $\left(2 \mathrm{mg}\right.$ of steroid in $0.5 \mathrm{~cm}^{3}$ DMSO). On the second day, solutions were replenished in all vessels by adding $10 \mathrm{~cm}^{3}$ of water or a solution of AN, respectively, to each vessel. For the next 3 days, the plants were watered daily with only distilled water $\left(30 \mathrm{~cm}^{3} / \mathrm{ves}\right.$ sel/day). Then, from the control group of plants, the aerial parts of seedlings (in the stage of two leaves) were sampled for analysis of endogenous androstenedione content. Next, a group of samples was collected from both the control and AN-treated plants to analyze the antioxidative system: (1) samples for measuring the activity of antioxidant enzymes (superoxide dismutase, catalase, and peroxidases) were collected from leaves and also from roots. (2) Samples for measuring superoxide dismutase isoforms and redox potential were taken from leaves. Finally, leaves and roots of the control and AN-treated plants were also sampled to assay phytohormones and sugars. The remaining vessels of control and AN-supplemented plants were placed in a growth chamber [temperature $5^{\circ} \mathrm{C}$, photoperiod $8 / 16 \mathrm{~h}$ (day/night)] for 15 days. During this period, the samples from both groups, were collected for phytohormone and sugar analyses every 3 days. On the 6 th and 15 th day of cold, samples 
from the two groups were collected for antioxidative system analysis. On the 15th day of cold, samples were taken from the control plants to assay the content of endogenous androstenedione. The remaining control and AN-treated plants were transferred from vessels to pots with soil and exposed to frost $\left(-12^{\circ} \mathrm{C}\right.$, darkness) in the growth chamber. The freezing cycle took place in the dark and was based on lowering the temperature by 3 degrees per $1 \mathrm{~h}$ starting at $5^{\circ} \mathrm{C}$ [at which the plants were acclimated (hardened)] until $-12{ }^{\circ} \mathrm{C}$ was reached. The plants were kept at $-12^{\circ} \mathrm{C}$ for $12 \mathrm{~h}$ and then the temperature was increased by 3 degrees every hour to $12^{\circ} \mathrm{C}$. The plants remained at $12^{\circ} \mathrm{C}(8 / 16 \mathrm{~h}$ photoperiod) for 1 day and subsequently the estimation of frost damage of leaves was performed.

\section{Design of Experiment 2}

Wheat seeds were disinfected, as described by Janeczko and others (2015), with 96\% ethanol, "Domestos" formulation, $\mathrm{HgCl}_{2}$ solution, and sterile distilled water. Seeds were then placed in Petri dishes and germinated in the dark for 3 days at $25^{\circ} \mathrm{C}$ on MS medium. The MS medium contained micro- and macroelements according to Murashige and Skoog (1962): 0.6\% agar, 3\% sucrose, $\mathrm{pH}=5.8$. After germination, seeds were cut off, to obtain sprouts with roots (that is, isolated embryos), which were transferred to Magenta vessels (GA-7, Sigma-Aldrich, Poznan, Poland) to fresh MS medium (control), and MS medium supplemented with AN. To obtain the desired AN concentration in the medium $(10 \mu \mathrm{M}), 2 \mathrm{mg}$ of AN was dissolved in $1 \mathrm{~cm}^{3}$ of $96 \%$ ethanol and appropriate amount of stock solution was added to the MS medium. Isolated wheat embryos were divided into six groups. Particular groups of embryos (containing both the control plants and plants on medium with AN) were exposed to cold (vernalized) in a growth chamber for a period of $0,3,6,9,12$, and 15 days at $5{ }^{\circ} \mathrm{C}$, photoperiod of $8 / 16 \mathrm{~h}$ (day/night). Seedlings were subsequently acclimated at $10^{\circ} \mathrm{C}$ for 7 days. Next, the plants were planted from in vitro culture into pots with soil, where the development was continued under the following conditions: photoperiod of $16 / 8 \mathrm{~h}$ (day/night); temperature $21 / 17^{\circ} \mathrm{C}$ (day/night). The advancement of generative development was evaluated at the end of the experiment.

\section{Design of Experiment 3 and Sampling}

Seeds were germinated in Petri dishes (2 days, darkness, $24^{\circ} \mathrm{C}$ ) and then transferred to two pots with soil (50 seeds per pot: $40 \times 15 \times 15 \mathrm{~cm}$ ). The pots with plants were kept for 7 days in a greenhouse at a temperature of $20^{\circ} \mathrm{C}$ (day/ night), under natural solar radiation (April, latitude: $50^{\circ} 30^{\prime}$ North, longitude: $19^{\circ} 55^{\prime}$ East). After this time, seedlings from one pot were picked up and aerial (upper) parts were separated from the root system and collected (control). The second pot with plants was placed in a growth chamber where it was exposed to a temperature of $5^{\circ} \mathrm{C}$ [photoperiod $8 / 16 \mathrm{~h}$ (day/night)] for 15 days. Then, the upper parts of seedlings were collected. The seedlings growing in cold were similarly developed (stage of two leaves) as seedlings from the first pot (not-cold-treated), because during cold exposure, plant growth is limited. Lipid fractions were isolated from cold-treated and not-cold-treated plants and AN interaction with native as well as model membranes was analyzed.

\section{Measurements and Observations}

\section{Estimation of Frost Damage of Leaves}

Frost damage to cell membranes results in the outflow of cell content (that is, the so-called electrolyte leakage). Visible dark areas on a leaf are a symptom of this, followed by its flabbing and withering. In experiment 1 , to evaluate the frost resistance, visual observations were carried out on plants from the control group and those treated with AN, which after hardening at $5{ }^{\circ} \mathrm{C}$ were exposed to $-12^{\circ} \mathrm{C}$. Two parameters were estimated: percentage of plants with frost damage of leaves compared to the total number of plants exposed to frost, and the size of the frost damage areaexpressed as a percentage of tissue damage to the surface of the whole leaf. This measurement was performed using a CI-202 Leaf Area Meter (CID Bio-Science, USA).

\section{Estimation of Advancement of Generative Development}

At the end of experiment 2, the stage of development of each plant was assessed individually. The measurement was performed for the AN-treated and control groups of plants exposed earlier to $0,3,6,9,12$, and 15 days of vernalization at $5{ }^{\circ} \mathrm{C}$. Plants were qualified to one of two groups: plants producing only leaves (vegetative) or plants in the generative stage of development. Plants in the generative stage of development included plants with a small spike hidden in the leaf sheath and generative-heading plants with a visible spike. Then the percentage of plants in the vegetative and generative stage was calculated for control and AN-treated groups.

\section{Analysis of Androstenedione}

The extraction and purification of AN were performed exactly as described earlier (Simerský and others 2009) using Strata $\mathrm{X}$ columns (Phenomenex, Torrance, CA, USA) and immunoaffinity columns [Laboratory of Growth Regulators (IEB ASCR \& Palacký University)]. AN was 
determined chromatographically using an UHPLC-MS/ MS system: ACQUITY UPLC ${ }^{\circledR}$ I-Class system (Waters, Milford, MA, USA) and a XevoTM TQ-S MS triple quadrupole mass spectrometer (Waters MS Technologies, Manchester, UK). The analysis was performed in triplicate. One replicate was a $1 \mathrm{~g}$ sample of fresh weight of aerial part of seedlings collected from independent plants.

\section{Analysis of Activity of Antioxidative Enzymes and SOD Isoforms}

For analysis, $0.5 \mathrm{~g}$ fresh weight of plant material was sampled and homogenized at $4^{\circ} \mathrm{C}$ in $50 \mathrm{mmol} \mathrm{dm}^{-3}$ of $\mathrm{K}_{\mathrm{Pi}}$ buffer (pH 7.0) containing $0.1 \mathrm{mmol} \mathrm{dm}{ }^{-3}$ EDTA. After centrifugation for $15 \mathrm{~min}$ at $10,000 \mathrm{~g}$, the supernatant was dialyzed for $24 \mathrm{~h}$ at $4{ }^{\circ} \mathrm{C}$. The prepared samples were assayed spectrophotometrically for the activity of superoxide dismutase (SOD), catalase (CAT), and peroxidases (POT). The activity of enzymes was expressed per mg of protein, where protein content was estimated spectrophotometrically using a modified method of Bradford (1976). The analyses were performed in triplicate.

SOD activity was determined spectrophotometrically using the cytochrome method (McCord and Fridovich 1969). The kinetics of the enzymatic reaction was studied using a KinLab program (Perkin Elmer, USA). Catalase activity was measured spectrophotometrically according to the procedure described by Aebi (1984). For the analysis, $0.05 \mathrm{~mol} \mathrm{dm}^{-3}$ phosphate buffer ( $\mathrm{pH} 7.0$ ) was used and $0.03 \mathrm{~mol} \mathrm{dm}^{-3}$ solution of $\mathrm{H}_{2} \mathrm{O}_{2}$ in the same buffer. The spectrophotometer was reset in pure buffer, followed by the addition of $0.5 \mathrm{~cm}^{3}$ of $\mathrm{H}_{2} \mathrm{O}_{2}$ solution and the two components were mixed. Then $50 \mu$ of tissue extract was added, and after 2-min mixing, decrease in absorbance was measured at $\lambda=240 \mathrm{~nm}$ at $20^{\circ} \mathrm{C}$. The reaction kinetics were determined using Specto Applications. The absorbance difference of 0.015 within $60 \mathrm{~s}$ was adopted as a unit of enzyme activity. POD activity was measured using a modification of the method of Lück (1962). The measurement was carried out using spectrophotometry at $\lambda=485 \mathrm{~nm}$. This was based on determining the amount of oxidation products of p-phenylenediamine in the presence of $\mathrm{H}_{2} \mathrm{O}_{2}$. The incubation mixture contained $3 \mathrm{~cm}^{3}$ of plant extract and $2 \mathrm{~cm}^{3}$ of $1 \%$ p-phenylenediamine in $0.05 \mathrm{~mol} \mathrm{dm}^{-3} \mathrm{~K}_{\mathrm{Pi}}$ buffer. The reaction was initiated by the addition $0.05 \mathrm{~cm}^{3}$ $0.03 \mathrm{~mol} \mathrm{dm}^{-3} \mathrm{H}_{2} \mathrm{O}_{2}$, and an increase in optical density was measured. The incubation time was selected so that the absorbance increase did not exceed 0.4 units. The reaction kinetics for both enzymes were measured 1 and 2 min after initiation of the reaction.

The analysis of SOD isoforms was performed by electrophoresis on a $13 \%$ polyacrylamide gel, according to the procedure previously described in the work of Hura and others (2014). The measurement was repeated five times.

\section{Estimation of Redox Potential}

Fresh plant material was incubated for $30 \mathrm{~min}$ in a mixture of $1 \mathrm{mmol} \mathrm{dm}^{-3}$ Tris- $\mathrm{HCl}$ buffer containing $0.5 \mathrm{mmol} \mathrm{dm}^{-3}$


tiated by adding $1 \mathrm{mmol} \mathrm{dm}^{-3}\left[\mathrm{~K}_{3} \mathrm{Fe}(\mathrm{CN})_{6}\right]$. The measurements of redox potential were carried out using cyclic voltammetry (CV) in a HPLC system (HPLC/ED, ESA Coulochem II, Beckman HPLC pump with a 5040 cell). The potential between the measuring ( $\mathrm{Au}$ ) and reference (Pt) electrode changed linearly from -800 to $1600 \mathrm{mV}$ (Chevion and others 2000). Oxygen was removed from each solution by $\mathrm{N}_{2}$ flow. The gold electrode was cleaned before each measurement (Oslonovitch and others 2003). The redox potential (E1/2) was calculated as the average of the peaks of the recorded voltammograms for the cathode and anode. The voltage values were compared with a calibration curve for standard solutions $\left[\mathrm{K}_{3} \mathrm{Fe}(\mathrm{CN})_{6}\right]$.

\section{Analysis of Phytohormones}

The plant material was lyophilized and pulverized after collection. Samples of $30 \mathrm{mg}$ of dry weight were prepared. Extraction and then purification [Bond Elut Plexa PCX columns (Agilent Technologies, USA)] were carried out as described in Dziurka and others (2016). Phytohormones [CKs, GAs, jasmonic acid (JA), ABA, salicylic acid (SA), auxins] were analyzed by ultrahigh performance liquid chromatography using an Agilent Infinity 1260 equipped with 6410 Triple Quad LC/MS with ESI (Electrospray Interface) (Agilent Technologies, USA) exactly as described by Dziurka and others (2016). The analysis was performed in triplicate.

\section{Sugar Analysis}

The content of soluble sugars was analyzed using high-performance liquid chromatography as described by Janeczko and others (2010). Samples of fresh plant material $(0.3 \mathrm{~g})$ were lyophilized and ground. Extraction was carried out on $5 \mathrm{mg}$ dry weight of samples. Analyses were performed in triplicate.

\section{Isolation of Lipids and Lipid Fractions}

Lipids were isolated from the plant material according to the Blight and Dyer (1959) method by extraction with the chloroform:methanol (1:2) mixture, as described in our earlier studies (Filek and others 2005). Fractions of phospholipids (PL), monogalactosyldiacylglycerols (MGDG), and 
digalactosyldiacylglycerols (DGDG) were obtained by separation on silica gel columns. The purity of fractions was analyzed by thin-layer chromatography. Qualitative and quantitative analysis of fatty acids were carried out chromatographically (Hewlett-Packard gas chromatograph, USA), as previously described in Filek and others (2010).

\section{Lipid Monolayer Preparation}

The Langmuir (Minitrough, KSV, Finland) technique was used to assess the physicochemical parameters of lipid monolayers (Rudolphi-Skórska and others 2014). The monolayers were prepared from PL, MGDG, DGDG fractions of lipids extracted from wheat plants cultured at 20 and $5{ }^{\circ} \mathrm{C}$, and additionally from the mixtures of PL with AN (Sigma-Aldrich; Poznań, Poland) in the ratio of 1:10 (w:w). Lipids, dissolved in chloroform, were spread on the surface of the water subphase in a Langmuir trough (total area of $243 \mathrm{~cm}^{2}$ ) or on $1 \times 10^{-5} \mathrm{M}$ aqueous solution of AN [the PL + AN mixture; proportion 1:20, 1:40 $(\% \mathrm{w} / \mathrm{w})]$ which was located only on the water subphase. The dependence of surface pressure versus area per lipid molecule $(\pi-A)$ was the basis for calculating the parameters of lipid monolayer structure. Surface pressure was stabilized with a Pt Wilhelmy plate suspended on an electrobalance. The subphase temperature (10, 25 or $35^{\circ} \mathrm{C}$ ) was maintained using a thermostat with an accuracy of $0.1{ }^{\circ} \mathrm{C}$. These temperatures were selected to mimic the possibility of different lipid molecular organizations in membranes at various environmental temperatures. The surface pressure was measured with an accuracy of $\pm 0.1 \mathrm{mN} / \mathrm{m}$ and area per molecule- $\pm 0.01 \AA^{2} /$ molecule.

\section{Statistical Analysis}

Statistical analysis of the results was made using the Statistica 10 (StatSoft, USA) program. Number of samples/repetitions is given in chapters describing particular measurements. Comparison of $>2$ averages (data in Table 1) was made using a Duncan test. Comparison of 2 averages (data in Tables 2, 3, Supplementary Table 1) was made using Student's $t$ test. Values marked with the same letters are not significantly differing. Averages presented in Figs. 1 and 2 were compared in pairs and statistical significance was calculated using a $\chi^{2}$ test (Fig. 1, left and Fig. 2) and Student's $t$ test (Fig. 1, right). Data presented on Figs. 3, 4, 5, 6, 7, 8, and 9 are mean values with standard deviations $( \pm$ SD). Graphs in Figs. 10 and 11 are exemplary results extracted directly from the program controlling the Langmuir bath.
Table 1 Surface parameters of monolayers $\left(A_{\text {lim }}\right.$-area/ molecule in condensed monolayer, $\pi_{\text {col }}$-surface pressure in condensed monolayer and $C_{\mathrm{s}}^{-1}$-molecular compressibility) calculated for monolayers of lipid fractions (PL—phospholipids, DGDGdigalactosyldiacylglycerols amd MGDG-

monogalactosyldiglycerols) obtained from plants cultured at 20 and $5^{\circ} \mathrm{C}$

\begin{tabular}{|c|c|c|c|c|}
\hline \multirow{2}{*}{$\begin{array}{l}\text { Plant growth temperature } \\
\left({ }^{\circ} \mathrm{C}\right) / \text { lipid fraction }\end{array}$} & \multirow{2}{*}{$\begin{array}{l}\text { Temperature of meas- } \\
\text { urement }\left({ }^{\circ} \mathrm{C}\right)\end{array}$} & \multicolumn{3}{|c|}{ Surface parameters of monolayer } \\
\hline & & $\overline{A_{\lim }\left(\AA^{2}\right)}$ & $\pi_{\mathrm{col}}(\mathrm{mN} / \mathrm{m})$ & $C_{\mathrm{s}}^{-1}(\mathrm{mN} / \mathrm{m})$ \\
\hline 20/PL & 10 & $57.45 \pm 0.04^{\mathrm{c}}$ & $41.15 \pm 0.02^{\mathrm{a}}$ & $52.66 \pm 0.09^{\mathrm{a}}$ \\
\hline 20/PL & 25 & $66.19 \pm 0.05^{\mathrm{b}}$ & $38.92 \pm 0.03^{\mathrm{b}}$ & $52.55 \pm 0.10^{\mathrm{a}}$ \\
\hline 20/PL & 35 & $67.00 \pm 0.07^{\mathrm{a}}$ & $36.41 \pm 0.03^{\mathrm{c}}$ & $43.64 \pm 0.11^{\mathrm{b}}$ \\
\hline $5 / \mathrm{PL}$ & 10 & $64.15 \pm 0.03^{\mathrm{c}}$ & $41.96 \pm 0.03^{\mathrm{a}}$ & $62.25 \pm 0.05^{\mathrm{a}}$ \\
\hline $5 / \mathrm{PL}$ & 25 & $74.17 \pm 0.06^{\mathrm{b}}$ & $40.78 \pm 0.05^{\mathrm{b}}$ & $62.01 \pm 0.08^{\mathrm{b}}$ \\
\hline $5 / \mathrm{PL}$ & 35 & $77.04 \pm 0.08^{\mathrm{a}}$ & $38.66 \pm 0.01^{\mathrm{c}}$ & $56.93 \pm 0.06^{\mathrm{C}}$ \\
\hline 20/DGDG & 10 & $84.61 \pm 0.12^{\mathrm{c}}$ & $40.74 \pm 0.05^{\mathrm{b}}$ & $78.40 \pm 0.10^{\mathrm{b}}$ \\
\hline 20/DGDG & 25 & $90.74 \pm 0.09^{b}$ & $41.83 \pm 0.04^{\mathrm{a}}$ & $78.74 \pm 0.08^{\mathrm{a}}$ \\
\hline 20/DGDG & 35 & $92.38 \pm 0.13^{\mathrm{a}}$ & $39.55 \pm 0.03^{c}$ & $77.79 \pm 0.09^{c}$ \\
\hline 5/DGDG & 10 & $81.93 \pm 0.08^{c}$ & $41.60 \pm 0.02^{\mathrm{a}}$ & $73.58 \pm 0.06^{\mathrm{a}}$ \\
\hline 5/DGDG & 25 & $89.45 \pm 0.07^{\mathrm{b}}$ & $41.47 \pm 0.04^{\mathrm{b}}$ & $73.54 \pm 0.07^{\mathrm{a}}$ \\
\hline 5/DGDG & 35 & $90.69 \pm 0.10^{\mathrm{a}}$ & $39.79 \pm 0.04^{c}$ & $73.31 \pm 0.09^{b}$ \\
\hline 20/MGDG & 10 & $63.59 \pm 0.12^{b}$ & $39.41 \pm 0.03^{\mathrm{a}}$ & $65.10 \pm 0.08^{\mathrm{a}}$ \\
\hline 20/MGDG & 25 & $70.47 \pm 0.08^{\mathrm{a}}$ & $37.90 \pm 0.07^{\mathrm{b}}$ & $65.23 \pm 0.12^{\mathrm{a}}$ \\
\hline 20/MGDG & 35 & $70.49 \pm 0.09^{\mathrm{a}}$ & $35.74 \pm 0.06^{\mathrm{c}}$ & $50.85 \pm 0.11^{b}$ \\
\hline 5/MGDG & 10 & $75.35 \pm 0.05^{\mathrm{c}}$ & $42.00 \pm 0.09^{\mathrm{a}}$ & $62.00 \pm 0.10^{\mathrm{a}}$ \\
\hline 5/MGDG & 25 & $78.11 \pm 0.07^{b}$ & $37.72 \pm 0.02^{\mathrm{b}}$ & $62.01 \pm 0.12^{\mathrm{a}}$ \\
\hline 5/MGDG & 35 & $84.76 \pm 0.04^{\mathrm{a}}$ & $35.06 \pm 0.05^{\mathrm{c}}$ & $47.32 \pm 0.10^{b}$ \\
\hline
\end{tabular}

Measurements were performed on the water subphase at 10,25 , and $35^{\circ} \mathrm{C}$. Data represent the means from three experiments \pm SE. Significant differences (Duncan test, $P \leq 0.05$ ) between monolayers formed at 10, 25 , and $5{ }^{\circ} \mathrm{C}$ for individual lipid fraction are indicated by different letters 
Table 2 Surface parameters of monolayers $\left(A_{\lim }\right.$-area/molecule in condensed monolayer, $\pi_{\text {col }}$-surface pressure in condensed monolayer and $C_{\mathrm{s}}^{-1}$ - molecular compressibility) calculated for monolayers of phospholipids fractions (PL) obtained from plants cultured at 20 and $5{ }^{\circ} \mathrm{C}$

\begin{tabular}{lllll}
\hline $\begin{array}{l}\text { Plant growth temperature }\left({ }^{\circ} \mathrm{C}\right) / \text { lipid } \\
\text { fraction }\end{array}$ & $\begin{array}{l}\text { Temperature of measurement } \\
\left({ }^{\circ} \mathrm{C}\right)\end{array}$ & \multicolumn{3}{l}{ Surface parameters of monolayer } \\
\cline { 2 - 4 } & & $A_{\lim }\left(\AA^{2}\right)$ & $\pi_{\text {col }}(\mathrm{mN} / \mathrm{m})$ & $C_{\mathrm{s}}^{-1}(\mathrm{mN} / \mathrm{m})$ \\
\hline $20 / \mathrm{PL}$ & 10 & $58.55 \pm 0.08^{\mathrm{b}}$ & $41.44 \pm 0.05^{\mathrm{a}}$ & $51.07 \pm 0.07^{\mathrm{a}}$ \\
20/PL & 25 & $72.10 \pm 0.12^{\mathrm{a}}$ & $39.98 \pm 0.06^{\mathrm{b}}$ & $50.87 \pm 0.05^{\mathrm{b}}$ \\
$5 / \mathrm{PL}$ & 10 & $64.11 \pm 0.10^{\mathrm{b}}$ & $41.60 \pm 0.04^{\mathrm{a}}$ & $58.73 \pm 0.08^{\mathrm{a}}$ \\
$5 / \mathrm{PL}$ & 25 & $74.62 \pm 0.09^{\mathrm{a}}$ & $40.12 \pm 0.06^{\mathrm{b}}$ & $50.64 \pm 0.10^{\mathrm{b}}$ \\
\hline
\end{tabular}

Measurements were made on the androstendione $\left(1 \times 10^{-5} \mathrm{M}\right)$ water solution as a subphase at 10 and $25^{\circ} \mathrm{C}$. Data represent the means from three experiments \pm SE. Significant differences (Student's $t$ test, $P \leq 0.05$ ) between monolayers formed at 10 and $25^{\circ} \mathrm{C}$ are indicated by different letters

Table 3 Surface parameters of monolayers $\left(A_{\lim }\right.$-area/molecule in condensed monolayer, $\pi_{\text {col }}$-surface pressure in condensed monolayer and $C_{\mathrm{s}}^{-1}$-molecular compressibility) calculated for monolayers of mixed phospholipids fractions (PL) and andriostendione (1:10; w: w)

\begin{tabular}{lllll}
\hline $\begin{array}{l}\text { Plant growth temperature }\left({ }^{\circ} \mathrm{C}\right) / \text { lipid } \\
\text { fraction }\end{array}$ & $\begin{array}{l}\text { Temperature of measurement } \\
\left({ }^{\circ} \mathrm{C}\right)\end{array}$ & \multicolumn{3}{l}{ Surface parameters of monolayer } \\
\cline { 2 - 5 } & & $A_{\text {lim }}\left(\AA^{2}\right)$ & $\pi_{\text {col }}(\mathrm{mN} / \mathrm{m})$ & $C_{\mathrm{s}}^{-1}(\mathrm{mN} / \mathrm{m})$ \\
\hline $20 / \mathrm{PL}$ & 10 & $60.36 \pm 0.10^{\mathrm{b}}$ & $41.60 \pm 0.07^{\mathrm{a}}$ & $47.28 \pm 0.04^{\mathrm{a}}$ \\
$20 / \mathrm{PL}$ & 25 & $66.90 \pm 0.11^{\mathrm{a}}$ & $39.05 \pm 0.03^{\mathrm{b}}$ & $46.80 \pm 0.05^{\mathrm{b}}$ \\
$5 / \mathrm{PL}$ & 10 & $68.97 \pm 0.14^{\mathrm{b}}$ & $41.31 \pm 0.06^{\mathrm{a}}$ & $58.28 \pm 0.02^{\mathrm{a}}$ \\
$5 / \mathrm{PL}$ & 25 & $75.72 \pm 0.09^{\mathrm{a}}$ & $40.24 \pm 0.05^{\mathrm{b}}$ & $48.20 \pm 0.08^{\mathrm{b}}$ \\
\hline
\end{tabular}

PL was obtained from plants cultured at 20 and $5^{\circ} \mathrm{C}$. Measurements were performed on water as a subphase at 10 and $25^{\circ} \mathrm{C}$. Data represent the means from three experiments \pm SE. Significant differences (Student's $t$ test, $P \leq 0.05$ ) between monolayers formed at 10 and $25^{\circ} \mathrm{C}$ are indicated by different letters
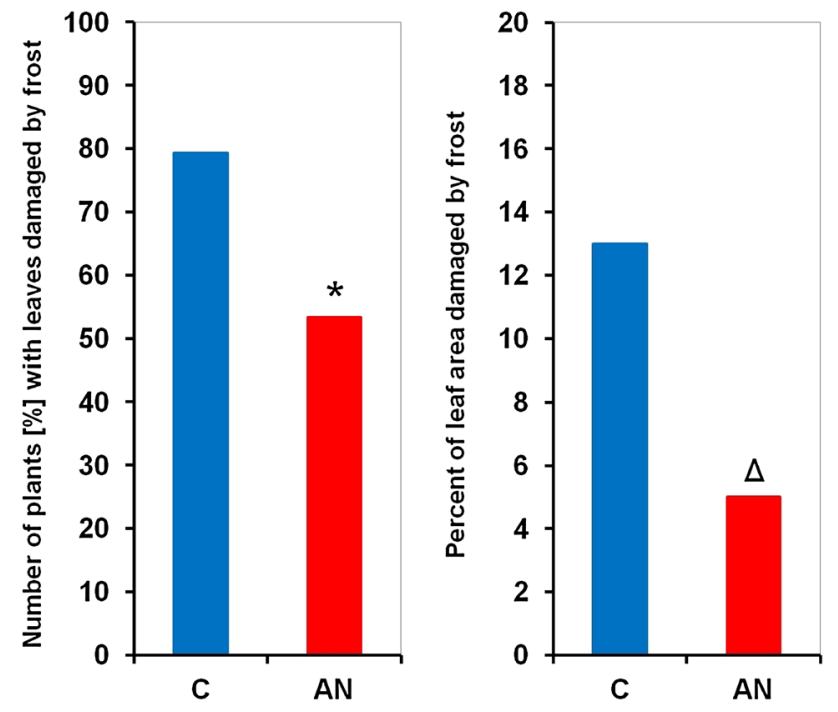

Fig. 1 The improvement of frost tolerance in wheat seedlings by androstenedione. Plants after 15 days of growing at $5^{\circ} \mathrm{C}$ were subjected to frost. *Represents statistically significant difference with respect to control based on $\chi^{2}$ test $(P \leq 0.05)$. $\Delta$ Represents statistically significant difference with respect to control based on Student's $t$ test $(P \leq 0.05)$

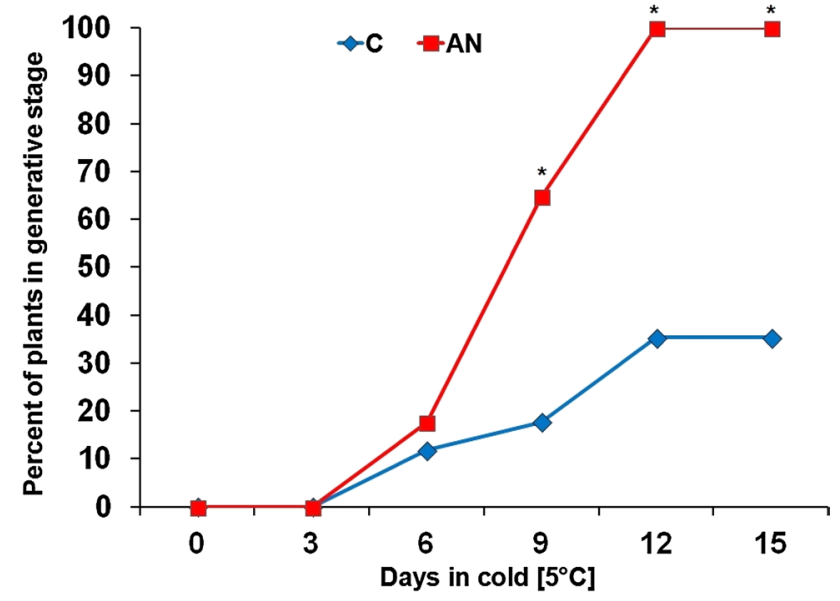

Fig. 2 Participation of androstenedione in the stimulation of generative development of wheat not exposed to cold (marked as ' 0 days in cold') and exposed to $5^{\circ} \mathrm{C}$ (3-15 days) at the seedling stage. Data expressed as a percentage of plants in the generative stage of development. *Represents statistically significant difference with respect to control based on $\chi^{2}$ test $(P \leq 0.05)$ 


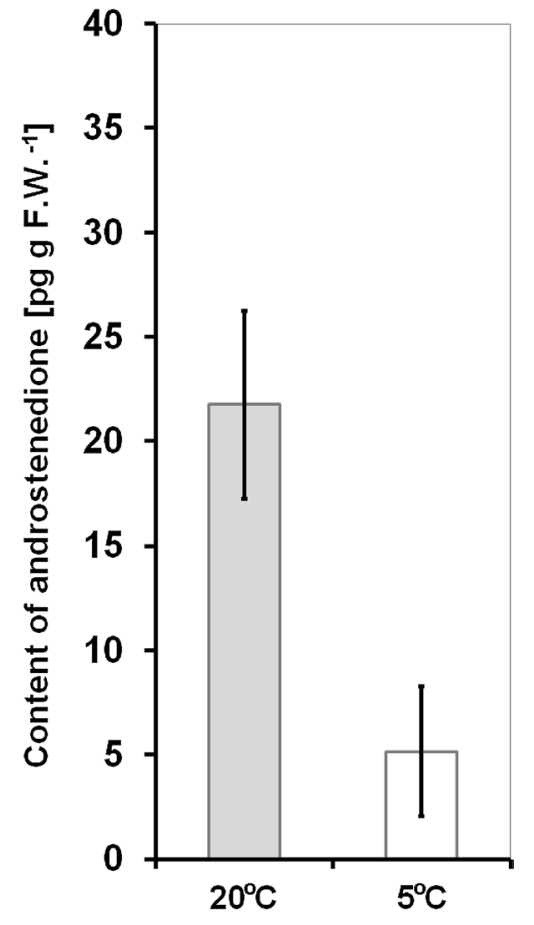

Fig. 3 Content of androstenedione in the leaves of wheat seedlings growing at $20^{\circ} \mathrm{C}$ and after 15 days of exposure to $5^{\circ} \mathrm{C}$. Mean values are shown with bars representing SD

\section{Results}

\section{Frost Tolerance and Generative Development of Wheat}

Androstenedione increased the frost tolerance of wheat and accelerated the generative development of the plants. In the group of control plants, due to the frost $\left(-12^{\circ} \mathrm{C}\right)$, about $80 \%$ of the plants were damaged (Fig. 1). AN supplementation reduced the number of damaged plants by $26 \%$. The observed damage in the control plants covered $13 \%$ of the leaf surface, whereas in the plants supplemented with AN this was only $5 \%$.

Non-vernalized (not exposed to cold) plants, and those that were exposed to a 3-day cold treatment, did not enter into the generative phase during the experiment (Fig. 2). Six-day cold resulted in the induction of generative development in less than $15 \%$ of plants. There was no effect of AN supplementation on the generative development when 0-6 days of cold was applied. The application of a 9-day cold treatment caused generative phase induction in $18 \%$ of the control plants and $65 \%$ of the plants treated with AN. The application of 12- and 15-day cold resulted in generative phase induction in approximately $35 \%$ of the control plants and $100 \%$ of the plants treated with AN.

\section{AN Content in Wheat}

AN was present in wheat seedlings growing at $20^{\circ} \mathrm{C}$ in the amount of 21.7 pmol g FW ${ }^{-1}$ (Fig. 3). After 15 days of cold exposure, the amount of AN decreased by four times.

\section{Antioxidant Enzymes and the Redox Potential of Tissues}

The activities of antioxidant enzymes (catalase, superoxide dismutase, and peroxidases) were measured in roots and aerial part of plants growing at $20^{\circ} \mathrm{C}$ and then after 6 and 15 days at $5^{\circ} \mathrm{C}$ (Fig. $4 \mathrm{a}-\mathrm{c}$, e-f). During cold exposure, the activity of CAT and POD decreased in the leaves of the controls by an average of $30 \%$, whereas SOD activity remained at the same level. In the leaves of ANtreated plants, the activity of all three enzymes significantly increased after exposure to $5^{\circ} \mathrm{C}$. The effect was spectacular after 15 days of cold when the activities of CAT and POD doubled, and SOD nearly quadrupled compared to the activity recorded at $20^{\circ} \mathrm{C}$. In the roots of the control plants, during cold exposure, the activity of CAT decreased after 6 days of cold but after 15 days it doubled in comparison to that measured at $20^{\circ} \mathrm{C}$. The activity of POT was the same before and during cold exposure in the control roots. SOD activity in the roots of controls had increased as early as 6 days in cold and remained at the same level after 15 days of cold exposure. Similar to the results obtained for aerial parts, the activity of all three enzymes increased gradually in the AN-treated plants during cold, and on day 15 of cold, it was several times higher than prior to cold exposure.

The following isoforms of SOD were found in the leaves of wheat: Cu/Zn SOD I, II, and MnSOD (Fig. 4h). Their accumulation decreased after 6 days of cold exposure but increased after 15 days of cold compared to those measured for plants growing at $20^{\circ} \mathrm{C}$. The accumulation of the isoforms (especially $\mathrm{Zn} / \mathrm{Cu} \mathrm{SOD}$ ) was the highest in the $\mathrm{AN}$ treated plants after 15 days of cold.

Changes in the redox properties of tissues were calculated based on the changes in the oxidation state of iron using the measurement of the redox potential. $\mathrm{Fe}^{3+}$ was introduced in excess to tissue extract, and changes in its content, demonstrating the oxidation of this compound to $\mathrm{Fe}^{2+}$, were the indicator of changes in the quantity of free electrons (radicals) in solution. During the control seedling growth in cold conditions, an increase in $\mathrm{Fe}^{3+}$ content was recorded, based on the amount of protein, compared to the results obtained for seedlings before cold application (Fig. 4d). The change was recorded on day 6 and further stay of plants in cold conditions resulted in only minor changes in redox potential. In plants treated with $\mathrm{AN}$, an additional increase (a few percent) in the $\mathrm{Fe}^{3+}$ 
Fig. 4 Changes in the efficiency of antioxidative system in wheat seedlings during 15 days of exposure to cold $\left(5^{\circ} \mathrm{C}\right)$ - the effect of androstenedione. The activity of antioxidative enzymes (CAT, POD, SOD) in the aerial part $(\mathbf{a}-\mathbf{c})$ and in roots $(\mathbf{e}-\mathbf{g})$; redox potential in leaves measured as changes in the concentration of $\mathrm{Fe}^{3+}(\mathbf{d})$; the activity of superoxide dismutase isoforms in leaves (h). Mean values (figures $\mathbf{a}-\mathbf{g}$ ) are shown with bars representing $\mathrm{SD}$
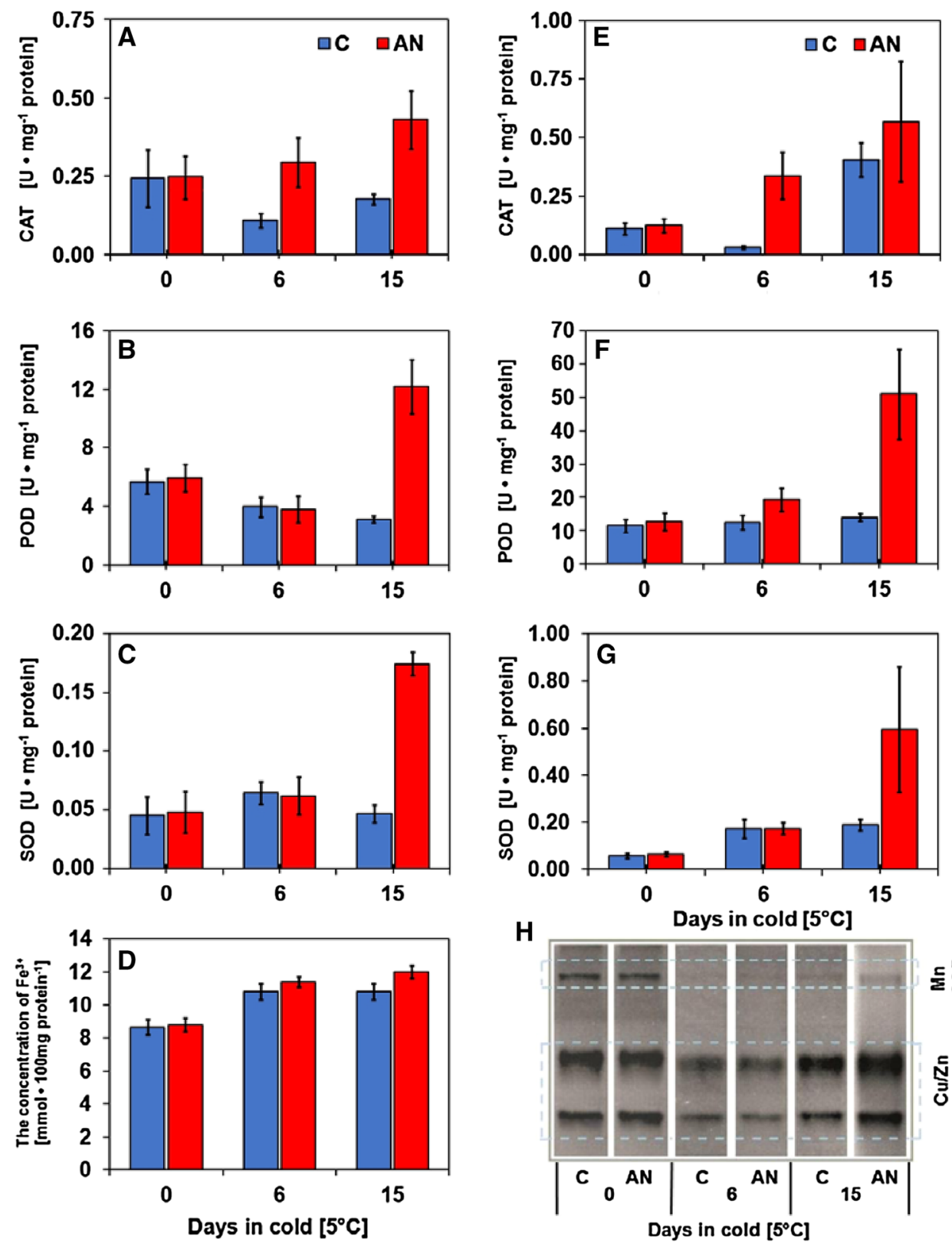

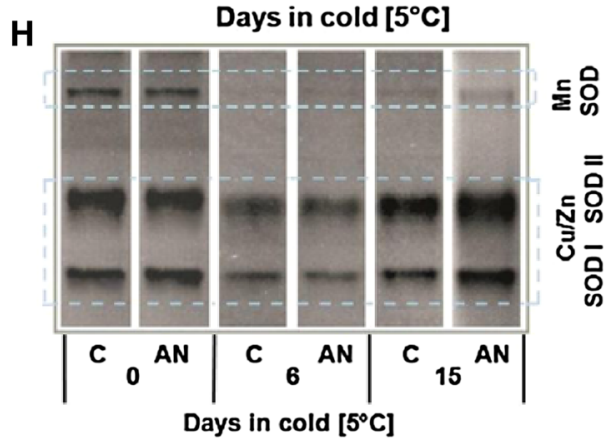

concentration was recorded in relation to the corresponding control plants.

\section{Content of Phytohormones}

\section{Cytokinins, Gibberellins, and Auxins}

The analysis of CK content in the wheat showed the presence of trans-zeatin, cis-zeatin, trans-zeatin riboside, ciszeatin riboside, N6-isopentenyladenine and N6-isopentenyladenosine (Fig. 5a-1).

In the aerial part of plants, these hormones were present in an amount of 10-100 of times higher than in the root. At the end of the cold period, the CK content usually decreased or remained unchanged both in the aerial part and the root of the control plants compared to the plants before cold treatment. A slight increase was recorded only in the case of N6-isopentenyladenine in the aerial part. In AN-supplemented plants (aerial part), the dynamics of CK changes during cold exposure were similar to the control, but cytokinin concentration was on average a little higher. This phenomenon was particularly evident on days 9 and 12 of cold exposure (Fig. 5a, b, d-f). In the root, compared to control, AN caused only very slight changes in the CK content with the exception of cis-zeatin ryboside. Roots of plants treated with AN accumulated about $20 \%$ more of this cytokinin before the cold exposure than the control 

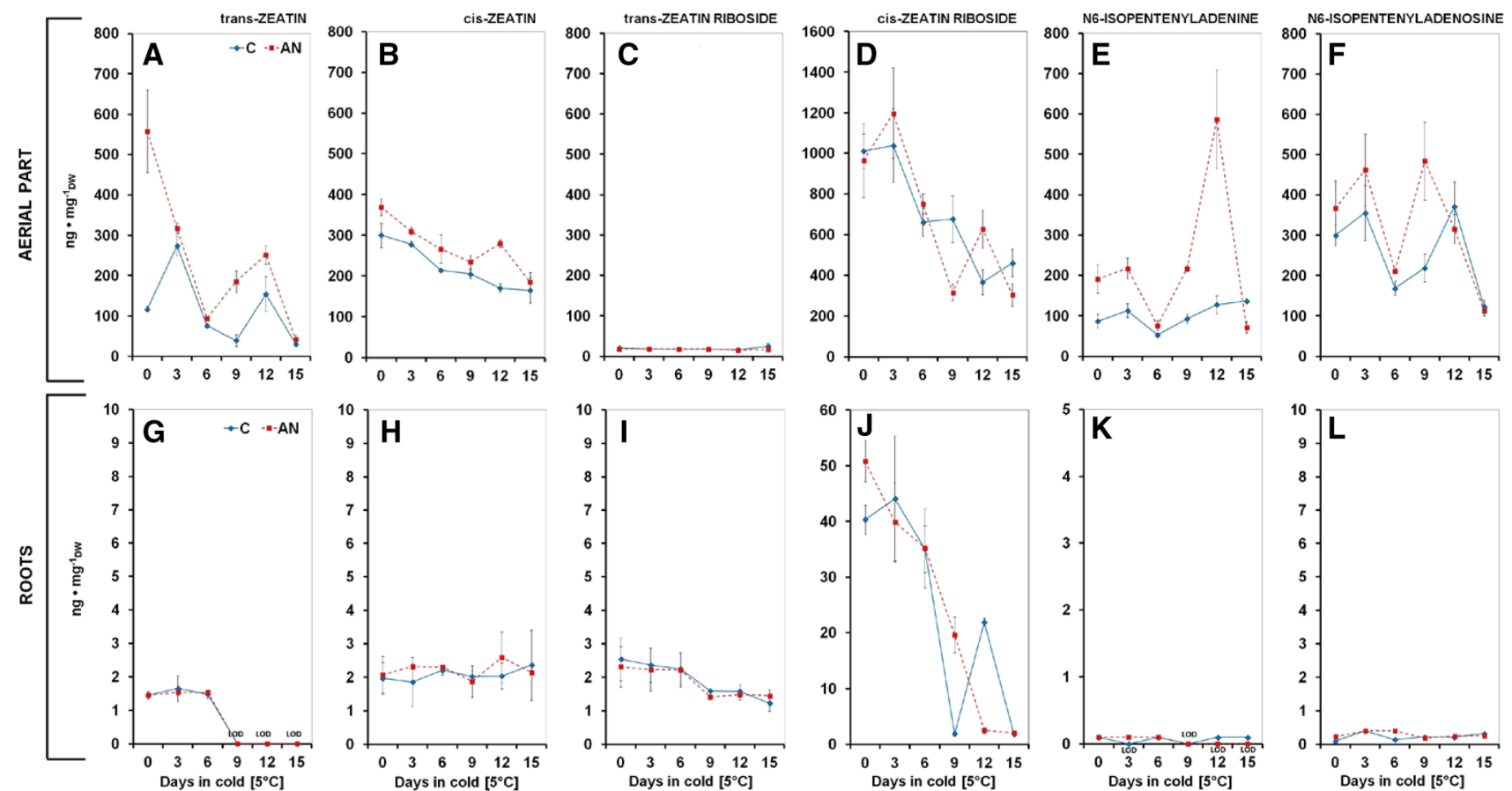

Fig. 5 Changes in the concentration of cytokinins in the aerial part $(\mathbf{a}-\mathbf{f})$ and in roots $(\mathbf{g}-\mathbf{l})$ of wheat seedlings during 15 days of exposure to cold $\left(5^{\circ} \mathrm{C}\right)$ - the effect of androstenedione. Mean values are shown with bars representing SD
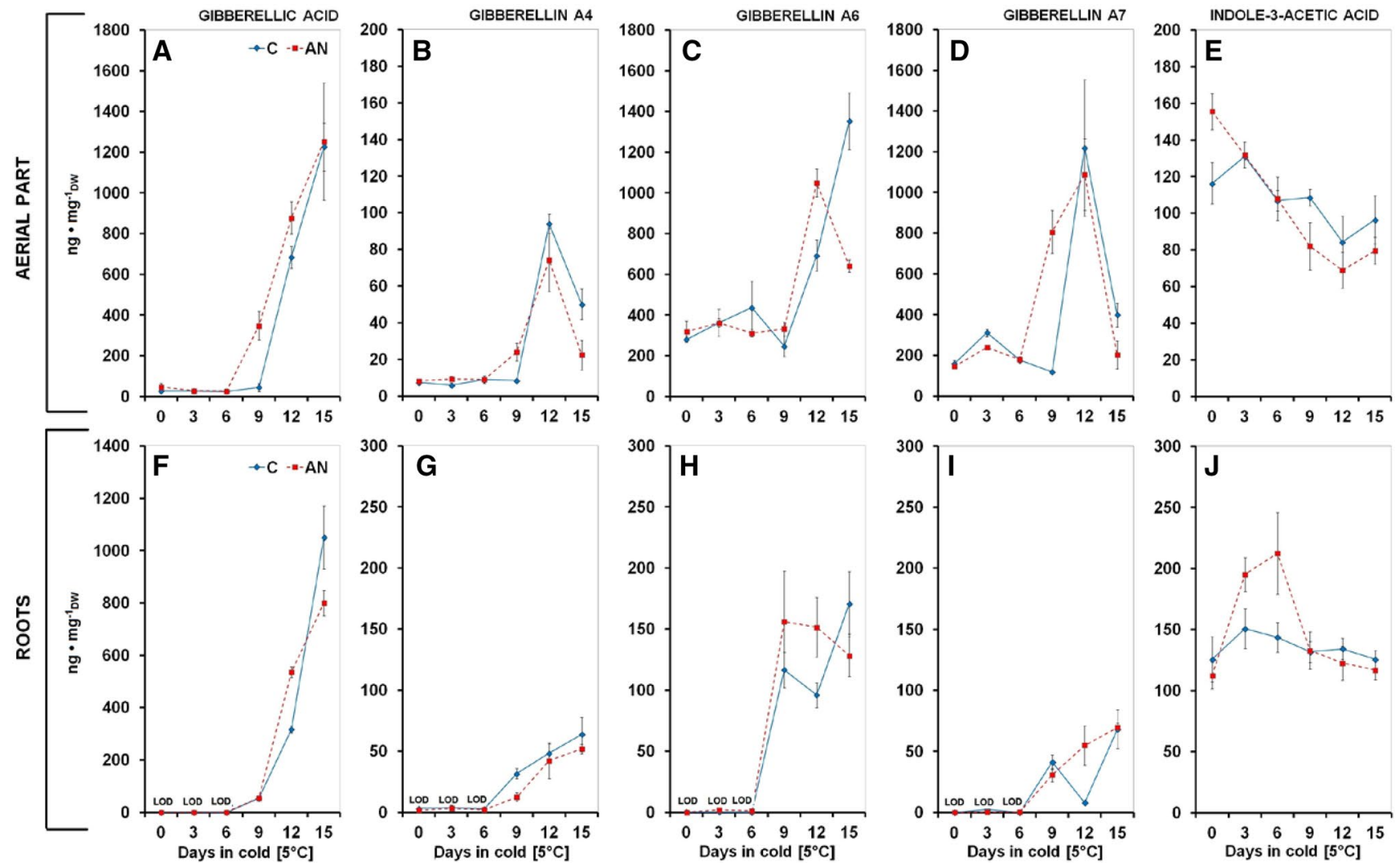

Fig. 6 Changes in the concentration of gibberellins and auxin (indole-3-acetic acid) in the aerial part (a-e) and in roots (f-j) of wheat seedlings during exposure to cold $\left(5^{\circ} \mathrm{C}\right)$ - the effect of androstenedione. Mean values are shown with bars representing SD 
Fig. 7 Changes in the concentration of abscisic acid, jasmonic acid, and salicylic acid in the aerial part $(\mathbf{a}-\mathbf{c})$ and in roots (d-f) of wheat seedlings during exposition to cold $\left(5^{\circ} \mathrm{C}\right)$ - the effect of androstenedione. Mean values are shown with bars representing SD
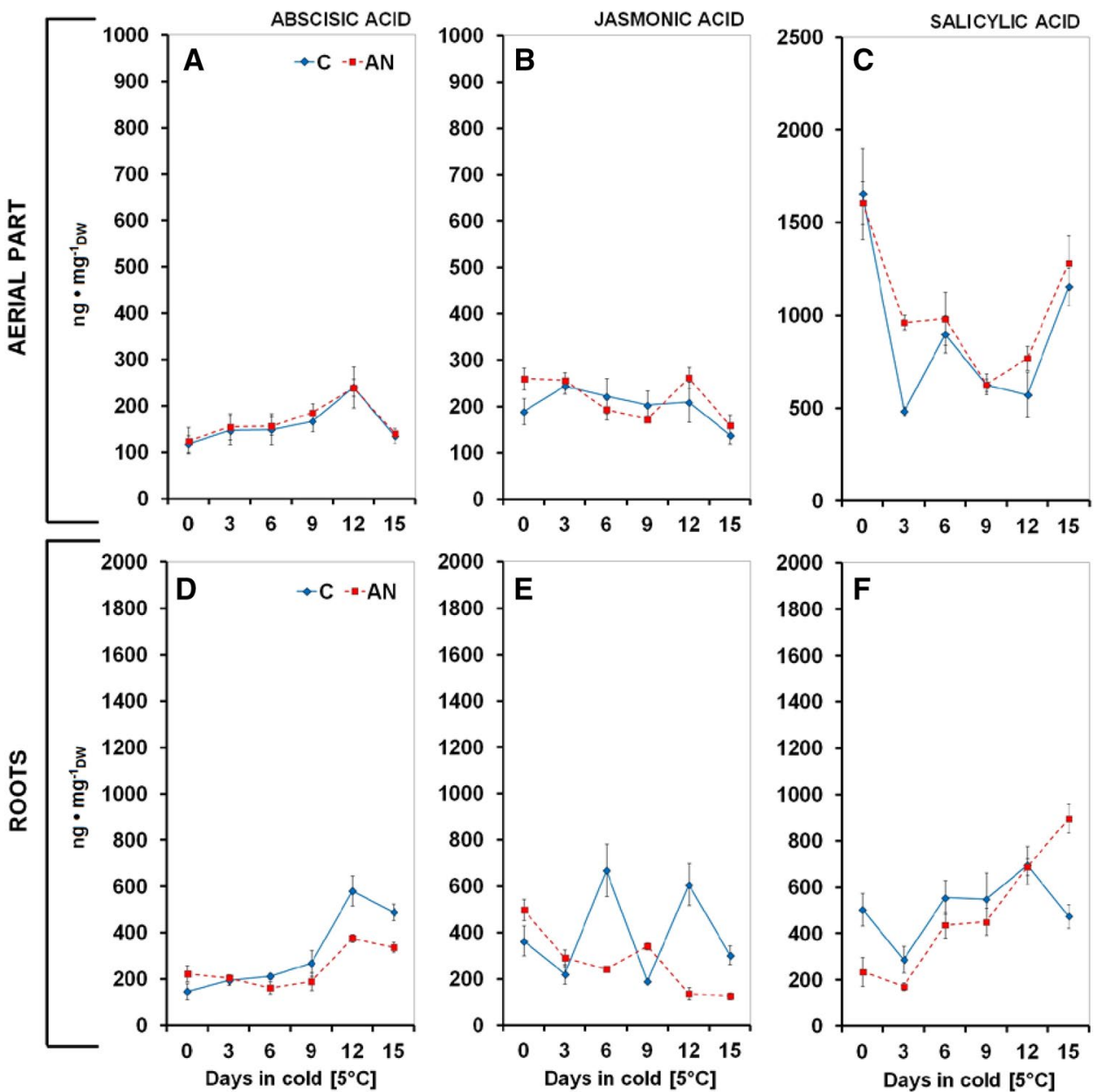

plants. On day 9 of cold exposure, the amount of the hormone in the AN-treated roots was higher than in the control, whereas on day 12 of cold, the content was decreased relative to control.

Of GAs, in the aerial part and roots, gibberellic acid and gibberellins A4, A6, and A7 were identified, whereas the content of gibberellin in the aerial parts was higher than in the roots (Fig. 6a-d, f-i). Cold increased the concentration of gibberellins both in the control and AN-treated plants. The aerial part of the control showed increased concentrations of gibberellic acid and gibberellins A4, A6, and A7 starting from day 12 of cold exposure. Thus, at the end of the cold period, the content of gibberellins was several times higher than in the notcold-treated plants as well as those exposed to cold for 3,6 , and 9 days. The dynamics of changes in the aerial parts of plants supplemented with $\mathrm{AN}$ were similar but the increase in the contents of gibberellic acid and gibberellins A4 and A7 occurred not on the 12th but on the 9 th day of cold. In roots, the increases were observed from day 9 of cold exposure in both the control and the
AN-treated plants. There were however differences in the content of particular gibberellins between the control plants and the AN-treated plants, depending on the duration of the cold period. On day 9, plants treated with AN had less A4, whereas on day 12, they had more gibberellic acid, A6, and A7 than the control plants. At the end of the cold period (day 15), the AN-treated plants had about $20 \%$ more only gibberellic acid, whereas other gibberellins were the same for both groups.

The only auxin detected in the aerial parts and roots of wheat was indole-3-acetic acid (IAA) (Fig. 6e, j). During cold, the IAA content in the aerial part significantly decreased and this effect was more spectacular in the ANsupplemented plants. In the roots, the dynamics of change were different. As regards to the control plants, the content of IAA remained practically unchanged after the cold period. In the roots of the AN-treated plants, a transient $30 \%$ increase in IAA concentration was observed on day 3 and 6 of cold exposure, and then a decline was detected in the following days down to the content recorded in the control. 

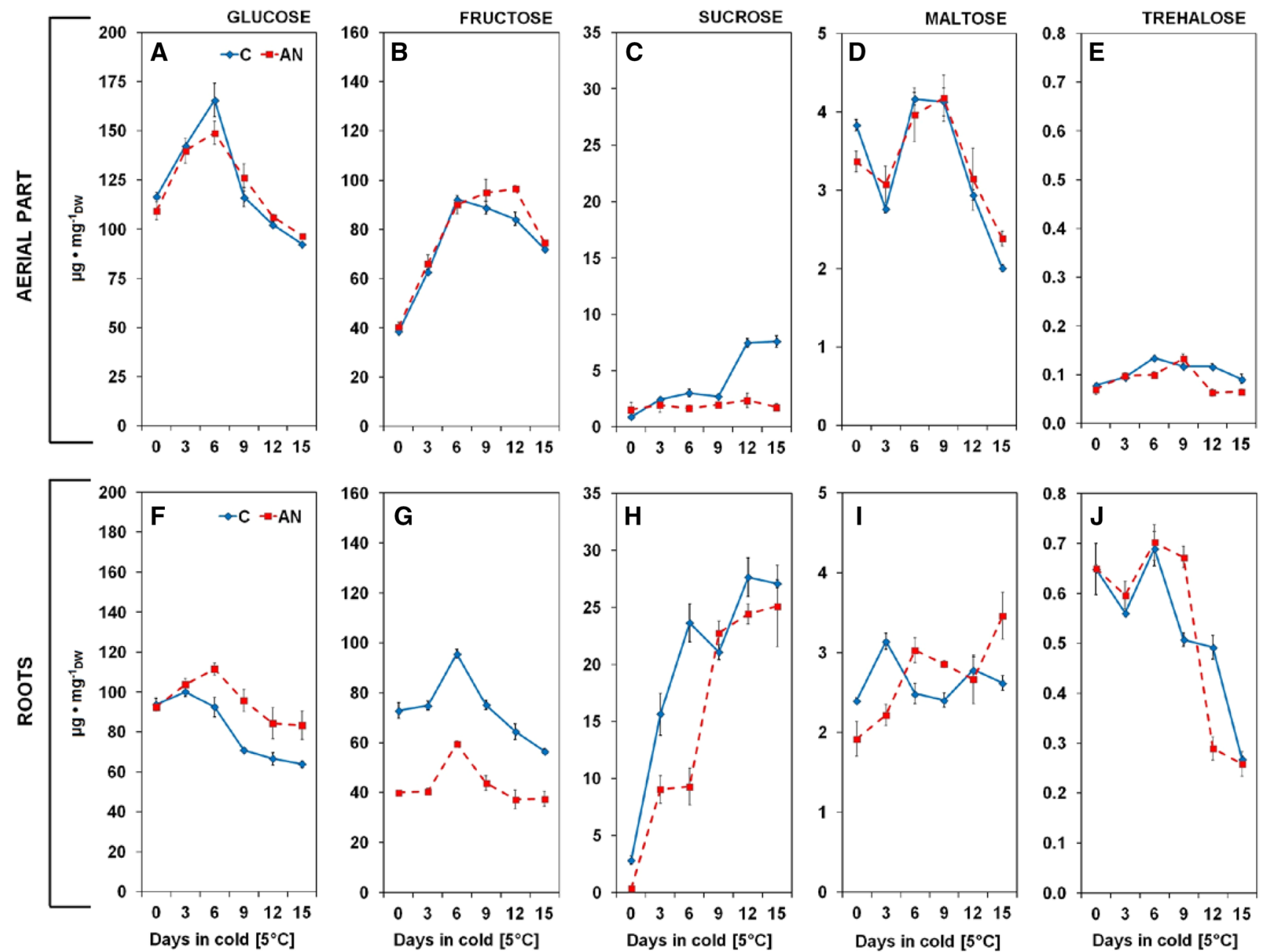

Fig. 8 Changes in the accumulation of mono- and disaccharides in the aerial part (a-e) and in roots (f-j) of wheat seedlings during exposure to cold $\left(5^{\circ} \mathrm{C}\right)$ - the effect of androstenedione. Mean values are shown with bars representing SD

\section{Stress Hormones}

Analysis of the so-called stress hormones in wheat revealed the presence of ABA, JA, and SA (Fig. 7a-c, d-f). In the aerial part, the concentration of all compounds except SA was on average several times lower than in the root. As a result of cold, the ABA content systematically increased in the control plants (aerial part) and those treated with $\mathrm{AN}$, where the maximum values were recorded on day 12 of the cold period. In the roots, a similar phenomenon was observed, although some AN-induced effects were observable. On day 12, the ABA content in the roots of the plants treated with $\mathrm{AN}$ was lower than in the control by about $1 / 3$, and this difference persisted until the end of cold exposure.

Before the latter, the JA content was higher on average by $20 \%$ both in the root and the aerial part of the ANtreated plants compared to control. About a $20 \%$ increase in the concentration of JA was noted in aerial parts of the control (on day 3). Later, the amount of JA decreased slightly.
In turn, in the aerial parts of the AN-treated plants, the JA content decreased during the cold exposure between days 3 and 9. On day 12, there was a large increase in JA content, but at the end of the cold period, the content of JA in the aerial parts of plants treated with $\mathrm{AN}$ was lower than before the cold exposure by about $40 \%$. The root of the control plants, both before and after the cold period, had the same content of JA; however, during cold exposure there were two large spikes in the JA content on days 6 and 12 . Changes in the JA content in the roots of the plants treated with AN had a different course than in the control. The JA levels decreased steadily as a result of the cold but on day 9 , there was a slight temporary increase in JA content. On day 15 of the cold period, JA concentration was five times lower in the root of the AN-treated plants than before cold exposure.

SA concentration in the aerial parts of wheat plants before cold was similar in the control plants and those treated with AN. The decrease in SA occurred between 
Fig. 9 Changes in the accumulation of tri- and tetrasaccharides in the aerial part $(\mathbf{a}-\mathbf{d})$ seedlings during exposure to cold $\left(5^{\circ} \mathrm{C}\right)$ - the effect of androstenedione. Mean values are shown with bars representing SD. LOD- too low to detect and in roots $(\mathbf{e}-\mathbf{h})$ of wheat
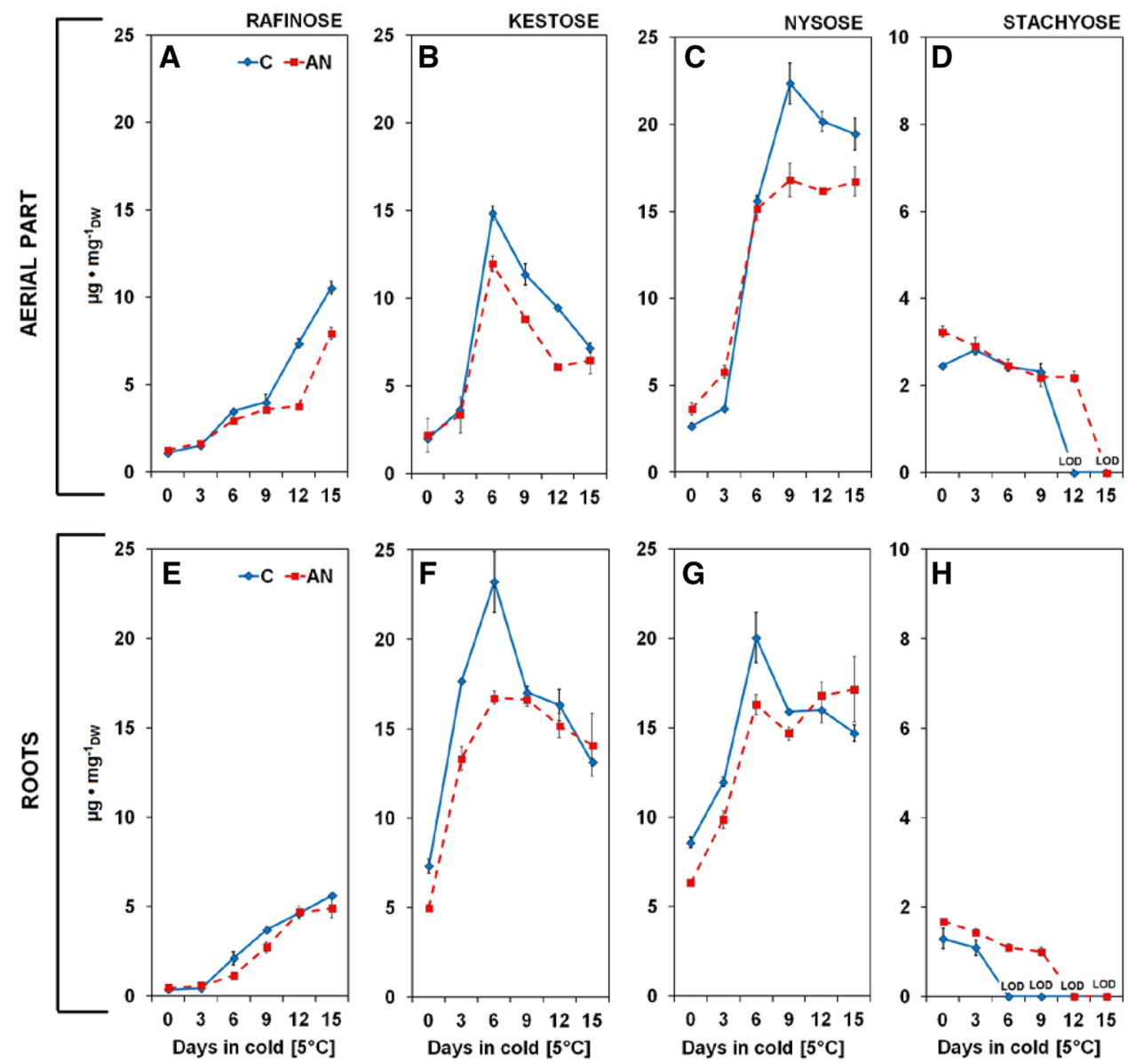

days 3 and 12. On day 15 of the cold period, SA concentration again increased, but to values a little lower than that recorded before cold. SA concentration in aerial parts of the AN-supplemented plants was higher than in controls only on day 3 of cold exposure. The roots of the AN-treated plants before cold exposure had a lower concentration of SA than the control plants. During the cold, SA content steadily increased to reach fivefold higher values on day 15 of cold exposure compared to the values noted before cold. In the control roots, despite fluctuations occurring between days 3 and 12 of cold exposure, the content of SA on the 15th day of cold reached the same level as before cold exposure.

\section{Sugar Content}

Significant changes were recorded in sugar content (monoand disaccharides-Fig. 8 and tri- and tetrasaccharidesFig. 9) as a result of cold exposure. AN supplementation in both aerial parts and roots modified the sugar accumulation.

A transient increase in glucose and fructose was found in the aerial part of the control wheat plants during cold exposure. On day 15 of cold exposure, glucose content was similar to the value recorded in the plants before cold, whereas the content of fructose was twofold higher than before the cold period. Simultaneously, between days 3 and 9 of cold exposure, the sucrose content remained at a similar level, but on days 12 and 15 it increased significantly, several times exceeding the content recorded before the cold. After a temporary decline in the accumulation of maltose on the third day of cold, there was an increase in the concentration of this sugar (days 6-9). However, at the end of the cold period (day 15), maltose content in aerial parts was twice as low as before cold. The content of trehalose changed only slightly in response to the cold. Changes in the accumulation of all these sugars in the aerial parts of the plants treated with AN were similar. The only exception was sucrose, which did not change as a result of cold exposure.

Glucose and fructose decreased by a few percent in the roots of the control plants in response to cold. At the same time, the sucrose content increased tenfold. Despite some (a few percent) fluctuations during cold, the maltose content was similar to that before the exposure to cold and after the cold period. The content of trehalose decreased more than twice as a result of the cold action. As a result of AN action, plant roots produced more glucose, less fructose, and sucrose (between days 3-6 of cold exposure); however, 
Fig. 10 Examples of relationships between surface pressure $(\pi)$ and surface molecules $(A)$ obtained from isotherms of Langmuir monolayers prepared from lipid fractions (PL, DGDG, and MGDG) extracted from plants cultured at 20 and $5^{\circ} \mathrm{C}$. Experiments were carried out at 10,25 , and $35^{\circ} \mathrm{C}$

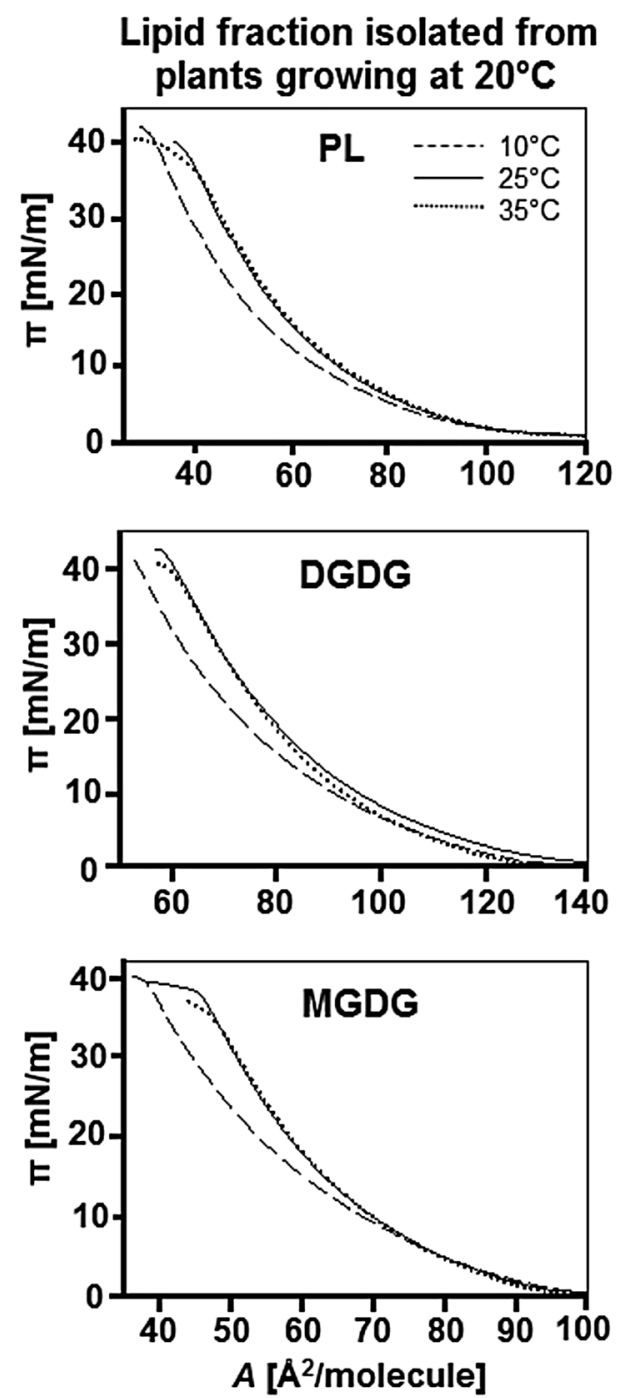

\section{Lipid fraction isolated from plants growing at $5^{\circ} \mathrm{C}$}
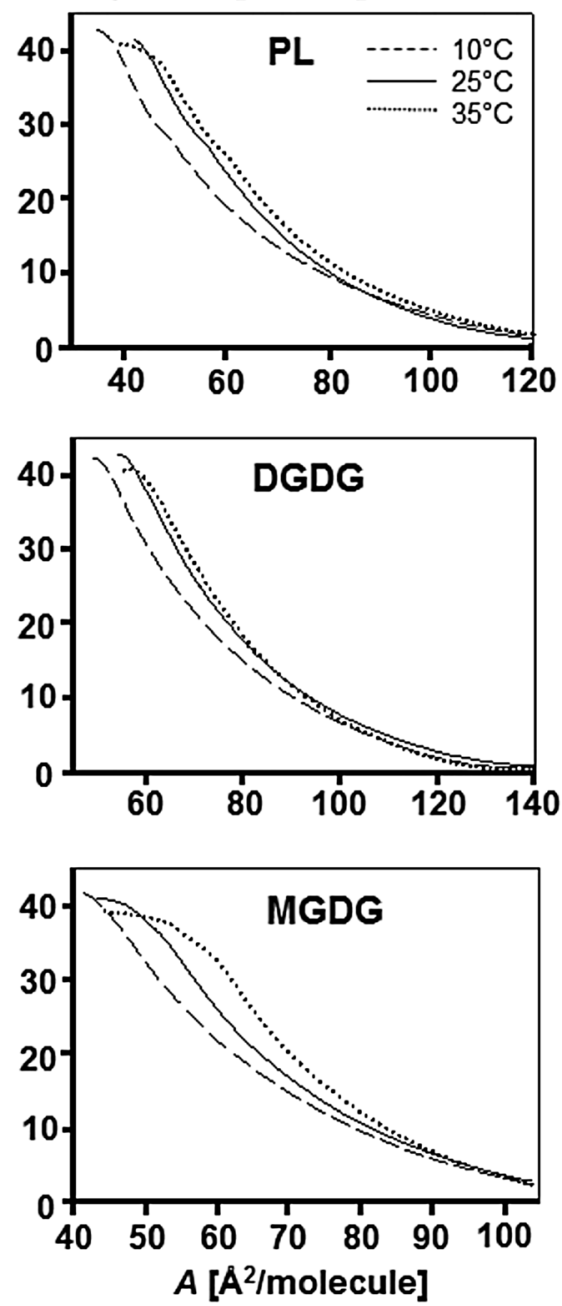

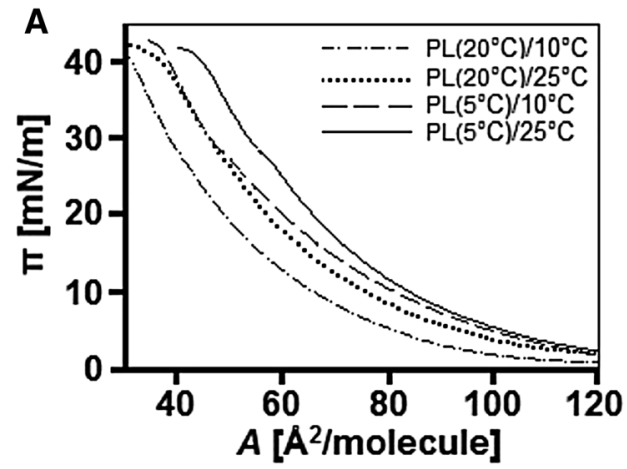

Fig. 11 Examples of relationships between surface pressure $(\pi)$ and surface molecules $(A)$ obtained from isotherms of Langmuir monolayers prepared from phospholipid fractions (PL), extracted from plants cultured at 20 and $5{ }^{\circ} \mathrm{C}$. The experiments were carried out at

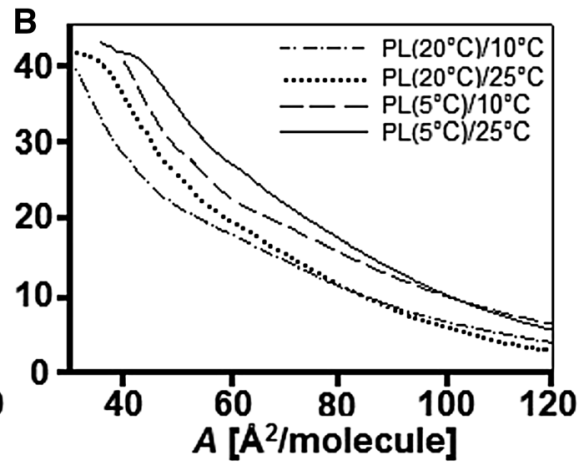

10 and $25^{\circ} \mathrm{C}$. a Lipid monolayers were built in the water solution of andriostendione $\left(10^{-5} \mathrm{M}\right)$ as a subphase. b Monolayers were built with lipid mixtures with andriostendione (1:10; w:w) 
the overall pattern of changes of these sugars was similar to that observed in the control. Likewise, the pattern of trehalose changes in the roots under AN action was similar to controls. In contrast to the control, the accumulation of maltose increased (approximately 30\%) in response to cold exposure in the roots of the plants treated with AN.

The content of raffinose and nystose in the aerial part increased several times in the control plants after the cold period. The amount of kestose was also increased, although the maximum occurred on day 6. Stachyose content was decreased due to cold, reaching finally values below the level of detection. The pattern of changes in the accumulation of these sugars in the aerial parts of plants exposed to AN was similar, although on the last day, they accumulated a few percent less of raffinose and nystose than control. At the same time, stachyose was detected longer (until day 12 of cold exposure) than in controls (to day 9).

Cold exposure induced accumulation of raffinose, kestose, and nystose in the roots of the control plants, and the final concentrations of these sugars (on day 15) increased 3-5 times relative to the accumulation recorded prior to cold. Similarly as in the aerial parts, stachyose content in the roots fell below the level of detection during cold. The roots of the plants treated with AN demonstrated a similar general pattern of changes in the concentrations of raffinose, kestose, nystose, and stachyose, as that observed in control. However, the roots under AN action accumulated a few percent less of kestose and nystose between days 3 and 6 of cold exposure than the control roots. In turn, the accumulation of stachyose persisted longer (until the 9th day of cold exposure) at the level of detection than in the control where stachyose could be detected only until day 3 .

\section{Interaction of Androstenedione with Model and Natural Membranes}

The lipid fractions extracted from plants growing at 20 and $5^{\circ} \mathrm{C}$ contained palmitic (16:0), palmitoleic acids (16:1) (mainly in galactolipids (DGDG and MGDG)), 16:3 (hexadecatrienoic acid), as well as stearic (18:0), oleic (18:1), linoleic (18:2), and linolenic acids (18:3) (Table 1, supplementary data). Plant growth at a lower temperature caused an increase in unsaturated fatty acid (determined as the 18:3/18:2 ratio) in all tested fractions. The greatest unsaturation changes were recorded for DGDG and MGDG, for which the C18:3 acid represented more than $50 \%$ of the content in relation to other fatty acids present in the lipid membrane.

The $\pi-A$ isotherms of PL, DGDG, and MGDG isolated from plants cultured at 20 and $5{ }^{\circ} \mathrm{C}$ are presented in Fig. 10. Monolayers of all lipids were found to be highly sensitive both to the temperature of plant cultures and the temperature of the measurements $\left(10,25\right.$ or $\left.35^{\circ} \mathrm{C}\right)$. Lipids obtained from plants grown at a lower temperature $\left(5^{\circ} \mathrm{C}\right)$ formed more expanded monolayers (higher maximal values of area/molecule) than the layers of lipids extracted from plants grown at $20^{\circ} \mathrm{C}$. Analyses of $\pi-A$ isotherm profiles taken at various temperatures indicated that lowering the temperature of the measurements led to the formation of more condensed monolayers. Detailed calculations of monolayer surface parameters $\left(A_{\text {lim }}\right.$-area/molecule in condensed monolayer, and $\pi_{\mathrm{col}}$-surface pressure corresponding to this state) are compiled in Table 1 .

Generally, higher values of $A_{\lim }$ were obtained for PL and MGDG lipid fractions which were extracted from plants cultured at $5{ }^{\circ} \mathrm{C}$ when compared to those grown at $20^{\circ} \mathrm{C}$ (Table 1). In contrast, the $A_{\text {lim }}$ parameter for DGDG showed a slightly lower value for fractions isolated from plants grown at $5{ }^{\circ} \mathrm{C}$ (than those for plants cultured at $10^{\circ} \mathrm{C}$ ). The increase of temperature of measurement resulted in an elevated $A_{\text {lim. }}$. Higher changes of $\Delta A_{\text {lim }}$ (differences between 10 and $35^{\circ} \mathrm{C}$ ) were detected for lipids obtained from plants cultured at $5^{\circ} \mathrm{C}$.

$\pi_{\mathrm{col}}$ parameters usually reached higher values for lipids extracted from plants grown at $5^{\circ} \mathrm{C}$, and decreased with an increase of measurement temperature for all investigated objects. Moreover, these changes were more visible for lipids obtained from plants developed at lower than at higher temperature.

To better characterize monolayer properties, a parameter describing the layer compressibility $\left(C_{\mathrm{s}}^{-1}\right)$ was determined as calculated according to the following formula (Davies 1961):

$C_{\mathrm{s}}^{-1}=\frac{d \pi}{d \ln A_{\mathrm{m}}}$,

where $A$ is the molecular area at the corresponding surface pressure $\pi$.

$C_{\mathrm{s}}^{-1}$ parameters were calculated at the pressure region of monolayers mimicking the lipid organization in natural biomembranes $(>30 \mathrm{mN} / \mathrm{m})$. The higher measurement temperature caused a decrease in $C_{\mathrm{s}}^{-1}$ parameter values for all lipid fractions. Moreover, for PL extracted from plants cultured at $5^{\circ} \mathrm{C}$, higher values of $C_{\mathrm{s}}^{-1}$ parameters (than for plants grown at $20^{\circ} \mathrm{C}$ ) were obtained, in contrast to both galactolipid fractions where lower values of $C_{\mathrm{s}}^{-1}$ were recorded for fractions extracted from objects grown at $5^{\circ} \mathrm{C}$.

When AN was introduced into the subphase, $A_{\lim }$ parameters of PL were higher than those obtained for lipids spread on pure water (compare Table 2 with Table 1). At a temperature of measurements equal to $10^{\circ} \mathrm{C}$, changes in $\Delta A_{\lim }$ (calculated between PL in surface contact with AN and with pure water) were smaller (about 1.10 and $0.04 \AA^{2}$ for $20^{\circ} \mathrm{C} / \mathrm{PL}$ and $5^{\circ} \mathrm{C} / \mathrm{PL}$, respectively) than that found at $25^{\circ} \mathrm{C}$ (abut 5.91 and $0.45 \AA^{2}$ for $20^{\circ} \mathrm{C} / \mathrm{PL}$ and $5^{\circ} \mathrm{C} / \mathrm{PL}$, respectively). $\pi_{\text {col }}$ parameters had values similar to those 
calculated for the water phase. The parameter characterizing monolayer compressibility was smaller in the presence of AN in the subphase.

When monolayers were prepared for mixtures of AN with PL (Fig. 11), increase in $A_{\text {lim }}$ values (comparison between PL + AN and pure PL) was also observed (Tables 1, 3). Moreover, for PL fraction extracted from plants grown at $20^{\circ} \mathrm{C}$, additional experiments were performed for the lipids:AN ratio equal to 1:20 and for ratio of 1:45 (\% w:w). The increase of AN content in the lipid layer by $20 \%$ caused an increase in $\Delta A_{\text {lim }}$ (in comparison to pure PL) to about 3.35 and $1.51\left(\AA^{2}\right)$, at a measurement temperature of 10 and $25^{\circ} \mathrm{C}$, respectively, whereas an AN level equal to $45 \%$ caused an increase in $\Delta A_{\lim }$ to about 18.67 and $3.01\left(\AA^{2}\right)$, at 10 and $25^{\circ} \mathrm{C}$, respectively.

$\pi_{\text {col }}$ parameters demonstrated similar values to those calculated for pure lipid monolayers and $C_{\mathrm{s}}^{-1}$ max parameters were smaller even than those obtained with $\mathrm{AN}$ in the water phase (Tables 2, 3).

\section{Discussion}

Thus far, the very few studies on the presence of AN and its role in plants have inspired us to conduct more detailed research on the mechanism of action of this mammalian androgen in plants. The present study demonstrated that AN is found in the cells of winter wheat and we investigated the biochemical and physicochemical changes induced by AN, associated with plant acclimatization to low temperatures.

Quantitative determination of the AN content showed the presence of this compound in wheat seedlings at concentrations similar to those recorded in Nicotiana tabacum L. and Inula helenium L.(Simerský and others 2009). However, after 15 days of cold, endogenous concentrations of AN did not increase [as expected by the authors and earlier observed for another steroid (brassinosteroids); Pociecha and others 2016], but was reduced. Pociecha and others (2016) underlined, that the first days of cold induced a stress response in the plant, and that exogenous supplementation with brassinosteroids before cold considerably increased the resistance to frost and pathogens (pink snow mold). A similar phenomenon may be occurring in the studied wheat. AN supplementation activated mechanisms that lead to reduction of frost damage of seedling leaves. Another androgen (androsterone) stimulated resistance to cold in maize plants, among others, by decreasing the membrane damage (also measured by electrolyte leakage) (Erdal 2012a). Improvement of the resistance to stress (for example, drought, salinity) through the application of AN and other androgens has also been reported by Janeczko and others (2012) and Erdal (2012b).
In turn, AN mediation in the stimulation of generative development of wheat was evidenced by an increase (compared to control) in the quantity of generative plants observed after a short vernalization (6-9 days). This is in agreement with earlier findings in Arabidopsis thaliana L. and also in other wheat cultivars (Janeczko and Filek 2002; Janeczko and others 2003).

Although we know some physiological effects induced in plants by AN, the mechanisms underlying the action of this steroid are unknown or very little has been learned about them. The biochemical background to the ANinduced stimulation of resistance mechanisms to low-temperature stress was verified by analyzing the activity of antioxidant enzymes-ROS (reactive oxygen species) scavengers. Direction and magnitude of changes in enzymatic activity of SOD, CAT, and POD are indirectly indicative of the amount of ROS and the capability of cells to tolerate their excess (Asada 1999). Changes in the redox balance, disturbed by the oxidation of biomolecules by ROS, have a signaling importance in the regulation of stress acclimation and development processes in plants (Fath and others 2002; Boldizsár and others 2011). Treatment of cereal plants with ROS and antioxidants improved the freezing tolerance and affected the expression of genes connected with it (Boldizsár and others 2011). Interestingly, fluctuations in the activity of the enzymatic antioxidant system are also characteristic for the preflowering and flowering period in date palm and during the development of apple flowers (Cheruth and others 2015; Abassi and others 1998). In oilseed rape, the formation of generative organs after a cold period was accompanied by an increase in the oxidation state of iron ions (Filek and others 2006). In our study, the increase in the activity of antioxidant enzymes during cold exposure and the recorded changes in redox potential (increased $\mathrm{Fe}^{3+}$ in relation to the oxidized $\mathrm{Fe}^{2+}$ ) indicated changes in the amount of ROS during the exposure to cold in wheat. The increase in the concentration of $\mathrm{Fe}^{3+}$, which occurred at the end of the cold period along with a simultaneous increase in the activity of antioxidant enzymes, demonstrated the effectiveness of the enzymatic system in ROS deactivation. This is aimed at maintaining the proper homeostasis in cells. In turn, the altered ratio of reduced components to oxidized components may be part of signaling in the cells, an important element in the process of generative induction. AN used in our experiment generally enhanced the intensity of the discussed phenomena. The plants treated with AN had a higher antioxidant enzyme activity and a greater concentration of $\mathrm{Fe}^{3+}$ on day 15 of cold exposure than the control plants. According to data obtained by Erdal (2012a), another androgen (androsterone) also stimulated resistance to cold in maize plants by activation of the antioxidative system. In conclusion, the AN-induced redox changes in the cells can be one of the factors responsible 
for higher frost resistance and subsequent acceleration of wheat generative development.

Plant acclimation to low temperature is always accompanied by hormonal alterations, especially the so-called stress hormones. During cold stress, hormones induce the expression of stress-related genes, maintain photosynthetic activity, activate antioxidant systems, regulate accumulation of osmoprotectants, and so on. The main player here is abscisic acid (ABA) (Churchill and others 1998). Jasmonic acid (JA) is another stress hormone, and the expression of biosynthetic genes of this compound, for example, in rice, is enhanced by the cold (Du and others 2013; Sharma and Laxmi 2015). Salicylic acid also induces multiple stress tolerance (Senaratna and others 2003). In our work, AN practically did not influence concentrations of stress hormones in aerial parts of plants. In roots, AN even decreased the contents of hormones such as ABA or JA. AN action, in this context, does not give grounds for concluding that the improvement of frost resistance of the tested wheat was due to the increased production of stress hormones induced by AN.

The control of development in the plant organism is a very complex process, involving the entire hormonal metabolism. However, the accumulation and mutual interactions of hormones, being cationic (CKs) and anionic organic substances (mainly GAs, but also auxins), are believed to play a more important role in the induction of generative development and regulation of plant flowering. Gibberellins are the most studied hormones that induce/regulate flowering (Mutasa-Göttgens and Hedden 2009). Lang (1952) demonstrated that application of gibberellic acid may substitute cold treatment in some species of plants requiring vernalization for flowering induction. Exogenous gibberellins in combination with a 2-week cold period stimulated the generative development of winter wheat (Biesaga-Kościelniak and others 2010). The increased levels of GAs during the period of generative development initiation, and a subsequent decrease in their concentrations were found during oilseed rape vernalization (Tarkowska and others 2012). In our experiment, the longer the time of exposure to cold, the higher the gibberellin content in the roots and aerial parts of plants. Control wheat accumulated more gibberellins (gibberellic acid, A4, A6, and A7) in the aerial parts starting from day 12 of cold exposure. An increase in the concentrations of GAs (in aerial parts of plants), induced by exogenous AN, occurred already after 9 days of cold. Nine days of cold was sufficient to induce the development of about $70 \%$ of AN-treated plants (in controls $<20 \%$ ). This result could suggest that AN-induced stimulation of generative development of wheat is gibberellin dependent, at least in part, because AN-induced stimulation of generative development of wheat may be also connected to activation of cytokinin metabolism. A transient increase in the content of almost all analyzed cytokinins in aerial parts of wheat (between day 9 and 12 of cold) was noted under AN action but not in controls. Correlation between higher cytokinin concentration and flowering induction is characteristic for some species-Chenopodium ssp., Sinapis alba L., Perilla frutescens (L.) Britt. (Mok and Mok 1994). The main effect of cytokinin deficiency in Arabidopsis thaliana L. is dwarfness but plants are also late-flowering (Eckardt 2003). In wheat, exogenous cytokinin applications, combined with 14 days of cold, stimulated generative development (Biesaga-Kościelniak and others 2010). The effect is not observed for exogenous auxin (Biesaga-Kościelniak and others 2010). Auxins can even inhibit plant flowering (Kulikowska-Gulewska and others 1995). These hormones rather function as plant growth stimulators. In AN-supplemented wheat, we observed enhanced decrease in auxin content (particularly in aerial part between 9 and 12 day of cold). A parallel increase of content of gibberellins and cytokinins can be interpreted as circumstances conducive to the stimulation of plant development by AN.

Sucrose is one of the most important soluble sugars whose high concentrations lower the freezing point of intracellular water in plants exposed to low temperatures. Moreover, high concentrations of sucrose mobilize the translocation of assimilates to the generative parts and activate genes associated with the induction of flowering (Kataoka and others 2004). In our experiment, sucrose content in the leaves and roots of control plants increased in cold. This was accompanied by reduced concentrations of two sucrose components (glucose and fructose). AN counteracted the phenomenon of cold-induced sucrose accumulation (in the aerial part of plant). Hence, it could not be stated that the improvement of frost resistance and acceleration of the generative development by AN was associated with its impact on the accumulation of increased amounts of sucrose. Sucrose is also a substrate in fructan synthesis and induces fructan synthesis genes (Müller and others 2000). Lower contents of two fructans: nystose (three units of fructose + one glucose) and kestose (two units of fructose + one glucose) in the AN-treated plants (comparing to control) may then result from lower accumulation of sucrose. Fructans serve as osmoprotectants and stabilize cell membranes by inserting polysaccharides into the lipid head region of the membrane (Hendry 1993; Livingston and Henson 1998). Due to the protective properties of fructans against abiotic stress, a decrease in their content may even weaken anti-stress mechanisms of the cold-exposed plants. Therefore, fructans rather did not participate in AN-induced improvement of frost resistance of wheat.

Rafinose and stachyose have ROS scavenging capacity (ElSayed and others 2014; Nishizawa-Yokoi and others 2008), thus they might help counteract oxidative stress of 
various origins. Trehalose also acts as an ROS scavenger as well as a stabilizer of cell membranes (Elbein and others 2003). In wheat seedlings (control), rafinose content increased as a result of cold. The AN-treated plants accumulated a few percent lower amounts of rafinose than the control plants. Simultaneously, stachyose content decreased during cold exposure in the control plants even to values close to 0 in aerial parts (from 12 day of cold) and in roots (from 6 day of cold). AN-treated seedlings produced stachyose longer and in higher amounts. Due to relatively low concentrations of these sugars (compared to glucose, fructose, sucrose, or fructans) in wheat, their role in the process of acclimation to cold probably should not be overestimated. The same concerns trehalose-sugar present in wheat in amounts below $1 \mu \mathrm{g}$ per mg DW. AN even slightly decreased the content of trehalose in the aerial part of plants, and thus this sugar also did not seem to be important in the AN-induced increase of wheat frost resistance.

According to Kaplan and Guy (2004), the experiments with temperature stress showed maltose accumulation (correlated with $\beta$-amylase induction) in chloroplast stroma. Maltose acted as an osmoprotectant and had a positive effect on the functionality of proteins, membranes, and membrane-associated processes, such as the photosynthetic electron transport chain. In our work, on day 15 of cold, the plants under AN action accumulated a few percent more of this sugar than controls. It is however difficult to say how important it was for the subsequent improvement of frost resistance, especially that maltose was present in wheat in amounts much less than other sugars, i.e., glucose, fructose, or sucrose.

In summary, changes in the accumulation of the analyzed sugars seem to appropriately characterize the response of control wheat to the cold, but the intensity of these changes and the level of sugar accumulation (with some exceptions) were not dramatically modified in the AN-treated plants. Hence, it does not appear that the ANinduced higher frost resistance was caused by the modulation of sugar metabolism. What is more, AN action in some cases (for example, a decrease in the sucrose content in the aerial part) should have even worsened frost resistance.

AN beneficial effects, especially in the improvement of plant frost resistance, may result from the interactions of these steroid with cell membranes. It is assumed that cell membranes act as thermal sensors (and/or contain sensors), which allow the plant to flexibly react to the changing temperature (Los and Murata 2004), and alterations in membrane fluidity play a significant role in this process. Changes in membrane fluidity can indirectly cause subsequent expression of genes that ensure acclimation to new environmental conditions (Los and others 2013). In turn, the change in membrane fluidity, in addition to the increase of fatty acid unsaturation, is affected by sterols (Laggner and others 2003) and compounds with a similar structure, which are incorporated into the membrane (Gzyl and others 2004).

In the present study, research was carried out that allowed to describe the interactions of AN with lipids present in the membranes of wheat plants. These interactions were verified by recording the dependence of changes in the surface pressure of the formed lipid monolayer in relation to the area occupied by lipid molecules in this model system (analysis using Langmuir technique). The applied model - a lipid monolayer/water (AN solution) — is equivalent to the system present at the interface of the membrane/ cytosol (apoplast) phases, and is used to study subtle relationships associated with the direct interaction of individual molecules with the cell membrane surface (Rudolphi-Skorska and Sieprawksa 2016). Physicochemical parameters $\left(A_{\text {lim }}, \pi_{\mathrm{col}}, C_{\mathrm{s}}\right)$ were determined for the lipids extracted from wheat membranes. These parameters characterize the differences in lipid structure of membranes and may be used to describe changes in native membranes, caused by physical (for example, temperature) and/or chemical (androstenedione) factors. We analyzed monolayers obtained from fractions of phospholipids (PL) and mono-(MGDG) and digalactosyl diglycerides (DGDG) of hardened $\left(5^{\circ} \mathrm{C}\right)$ and non-hardened $\left(20^{\circ} \mathrm{C}\right)$ wheat plants. A comparison of physicochemical parameters of monolayers allowed us to demonstrate that the distances between lipid molecules (concerning mainly PL and MGDG fractions) were higher in the membranes of hardened plants than in the membranes of non-hardened plants. This is due to the presence of polyunsaturated fatty acids (mainly 18:3) in the hydrophobic parts of lipids of these fractions, which were present in a higher proportion (relative to other fatty acids) in the membranes of hardened plants. Lowering the measurement temperature (from 35 to $5^{\circ} \mathrm{C}$ ) of the model monolayer resulted in a higher lipid arrangement in the monolayers and a decrease in the distance between adjacent molecules (decrease in the kinetic energy of lipids).

Introduction of AN (at a concentration of $1 \times 10^{-5} \mathrm{M}$ ) to an aqueous solution, on the surface of which the monolayers were formed, resulted in an increase of the distance between lipid molecules in the monolayer. This was caused by the penetration of the monolayer by $\mathrm{AN}$, absorbed from the solution surrounding the monolayer. The highest AN incorporation in the monolayer was obtained at a higher temperature and for lipids extracted from non-hardened plants. This demonstrated that the exogenous application of AN to wheat plants before the start of the cold period might result in modification of the membrane structure to better prepare for stressful conditions. When AN was introduced directly to the lipids (mixture of PL $+\mathrm{AN}$ ), and monolayers were prepared from such mixtures, an increase in the distance between lipid molecules was also demonstrated. 
However, then, higher distances between the lipid particles were obtained at a lower temperature, and for the lipids isolated from hardened plants.

As mentioned above, in the membranes of hardened plants (and therefore with already acquired frost resistance), the distances between lipid molecules are larger than in the membranes of non-hardened plants. A similar effect (increase in the distance between lipid molecules in a monolayer) was obtained when $\mathrm{AN}$ was introduced in the aqueous solution on the surface of which the monolayers were obtained. AN incorporation in the membranes, changing their physicochemical properties, may therefore be an important step in the mechanism of formation of frost resistance induced by AN. At the same time, AN interaction with lipid membranes showed similarities to the interactions of some of the known regulators stimulating the flowering of plants (Filek and others 2002, 2005), therefore, they can also be involved in the acceleration of wheat development.

\section{Concluding Remarks}

Our work provides new knowledge about the presence of mammalian androgen in plants, especially in winter wheat. The study shows the multidirectional activity of AN in regulating plant metabolism (hormonal management, carbohydrate accumulation, antioxidant system). Of particular novelty are studies devoted to the interaction of AN with model and natural plant membranes, and its relation to the development of temperature stress resistance. Taking all our results into account, in our opinion, more attention should be devoted to studies of the role of steroids (not only androgens but also others-progesterone, brassinosteroids) particularly in frost resistance in winter plants. This could lead to the development of agrochemicals useful for plant protection against abiotic stress or help to breed new cultivars with improved resistance.

To summarize:

- Androstenedione is present in wheat but its content diminishes as a result of 2-week exposure to cold.

- AN enhances frost resistance and accelerates the generative development of wheat.

- Mechanisms of AN action are connected to regulation of activity of enzymatic antioxidants, and some changes in sugar accumulation and hormonal management. The enhanced frost resistance due to AN should be sought in the activation of the antioxidant system. The ANinduced changes in redox homeostasis are probably also involved in the signaling necessary for generative induction. The impact of AN on hormone (stress hormones) and sugar metabolism does not seem to be relevant for improving frost resistance or stimulating generative induction. In certain cases (results for sucrose), AN even abolished the effects induced by cold. Stimulating the production of certain flowering hormones (mainly gibberellins) can be considered an AN mechanism accelerating generative development.

- The enhanced frost resistance may also be connected to the impact of AN on cell membranes. AN can be absorbed either into plant membranes, when present in the hydrophilic solution surrounding the membrane and when found in association with hydrophobic molecules. The degree of membrane penetration by AN depends on the membrane composition (saturated/unsaturated fatty acids), which is modified by plant growth conditions (room temperature/cold exposed) and the temperature of measurement. The composition of the solution (aqueous or organic solution), in which the compound is dissolved also affects membrane penetration. However, in general, the membrane absorption of AN and steroid-induced increase in the distance between lipid molecules may be important steps in the formation of frost resistance by AN. AN interactions with lipid membranes showed also similarities to the interactions of some of the known regulators stimulating the flowering of plants, and thus they can also underlie the acceleration of wheat development.

Open Access This article is distributed under the terms of the Creative Commons Attribution 4.0 International License (http:// creativecommons.org/licenses/by/4.0/), which permits unrestricted use, distribution, and reproduction in any medium, provided you give appropriate credit to the original author(s) and the source, provide a link to the Creative Commons license, and indicate if changes were made.

\section{References}

Abassi NA, Kushad MM, Endress AG (1998) Active oxygen-scavenging enzymes activities in developing apple flowers and fruits. Sci Hortic 74:183-194

Adler JH, Grebenok RJ (1999) Occurrence, biosynthesis, and putative role of ecdysteroids in plants. Crit Rev Biochem Mol Biol 34:253-264

Aebi H (1984) Catalase in vitro. Methods Enzymol 105:121-125.

Asada K (1999) The water-water cycle in chloroplasts; scavenging of oxygen and dissipation of excess photons. Ann Rev Plant Mol Biol 50:601-639

Awasthi R, Bhandari K, Nayyar H (2015) Temperature stress and redox homeostasis in agricultural crops. Front Environ Sci $3: 1-24$

Beck EH, Heim R, Hansen J (2004) Plant resistance to cold stress: mechanisms and environmental signals triggering frost hardening and dehardening. J Biosci 29:449-459

Bernier G, Périlleux C (2005) A physiological overview of the genetics of flowering time control. Plant Biotechnol J 3:3-16 
Biesaga-Kościelniak J, Kościelniak J, Filek M, Marcińska I, Krekule J, Machackova I, Kuboń M (2010) The effect of plant growth regulators and their interaction with electric current on winter wheat development. Acta Physiol Plant 32:987-995

Blight EG, Dyer WJ (1959) A rapid method of total lipids extraction and purification. Can J Biochem 37:911-915

Boldizsár Á, Gulyás Z, Carrera D, Soltész A, Vashegyi I, Szalai G, Galiba G, Kocsy G (2011) Redox regulation of cold acclimation and vernalization in wheat. Acta Biol Szeged 55:63-66.

Bradford M (1976) A rapid and sensitive method for the quantitation and sensitive of microgram quantities of protein utilising the principle of protein-dye binding. Anal Biochem 72:248-254

Cheruth AJ, Kurup SS, Subramaniam S (2015) Variations in hormones and antioxidant status in relation to flowering in early, mid, and late varieties of date palm (Phoenix dactylifera) of United Arab Emirates. Sci World J 2015:846104

Chevion S, Roberts MA, Chevion M (2000) The use of cyclic voltammetry for the evaluation of antioxidant capacity. Free Radic Biol Med 28:860-870

Churchill GC, Reaney MJT, Abrams SR, Gusta LV (1998) Effects of abscisic acid and abscisic acid analogs on the induction of freezing tolerance of winter rye (Secale cereale L.) seedlings. Plant Growth Regul 25:35-45

Davies JT (1961) Interfacial phenomena. Academic Press Inc, New York

Davies PJ (2010) Plant hormones: biosynthesis, signal transduction, action!, 3rd edn. Springer-Verlag, New York

Diallo AO, Ali-Benali MA, Badawi M, Houde M, Sarhan F (2012) Expression of vernalization responsive genes in wheat is associated with histone $\mathrm{H} 3$ trimethylation. Mol Genet Genom 287:575-590

Du H, Liu H, Xiong L (2013) Endogenous auxin and jasmonic acid levels are differentially modulated by abiotic stresses in rice. Front Plant Sci 4:397

Dziurka M, Janeczko A, Juhász C, Gullner G, Oklestková J, Novák O, Saja D, Skoczowski A, Tóbiás I, Barna B (2016) Local and systemic hormonal responses in pepper leaves during compatible and incompatible pepper-tobamovirus interactions. Plant Physiol Biochem 109:355-364

Eckardt NA (2003) A new classic of cytokinin research: cytokinindeficient arabidopsis plants provide new insights into cytokinin biology. Plant Cell 15:2489-2492

Elbein AD, Pan YT, Pastuszak I, Carroll D (2003) New insights on trehalose: a multifunctional molecule. Glycobiology 13:17R-27R

ElSayed AI, Rafudeen MS, Golldack D (2014) Physiological aspects of raffinose family oligosaccharides in plants: protection against abiotic stress. Plant Biol (Stuttg) 16:1-8

Erdal S (2012a) Androsterone-induced molecular and physiological changes in maize seedlings in response to chilling stress. Plant Physiol Biochem 57:1-7

Erdal S (2012b) Alleviation of salt stress in wheat seedlings by mammalian sex hormones. J Sci Food Agric 92:1411-1416

Fath A, Bethke P, Belligni V, Jones R (2002) Active oxygen and cell death in cereal alereal aleurone cell. J Exp Bot 53:1273-1282

Filek M, Zembala M, Szechynska-Hebda M (2002) The influence of phytohormones on zeta potential and electrokinetic charges of winter wheat cells. Z Naturforsch C 57:696-704

Filek M, Biesaga-Kościelniak J, Marcińska I, Krekule J, Machackova I, Dubert F (2003) The effect of electric current on flowering of grafted scions of non-vernalized winter rape. Biol Plant 46:625-628

Filek M, Gzyl B, Laggner P, Kriechbaum M (2005) Effect of indole3 -acetic acid on surface properties of the wheat plastid lipids. J Plant Physiol 162:245-252
Filek M, Mirek M, Dlugolecka M (2006) Changes of redox activity during the development of rape. Z Naturforsch C 61:548-552

Filek M, Biesaga-Kościelniak J, Macháčkova I, Krekule J (2007) Generative development of Winter rape (Brassica napus L.): the role of vernalization. Int J Plant Develop Biol 1:57-63

Filek M, Gzyl-Malcher B, Zembala M, Bednarska E, Laggner P, Kriechbaum M (2010) Effect of selenium on characteristics of rape chloroplasts modified by cadmium. J Plant Physiol $167: 28-33$

Gusta LV, Trischuk R, Weiser CJ (2005) Plant cold acclimation: the role of abscisic acid. J Plant Growth Regul 24:308-318

Gzyl B, Filek M, Dudek A (2004) Influence of phytohormones on polar and hydrophobic parts of mixed phospholipid monolayers at water/air interface. J Colloid Interface Sci 269:153-157

Hendry GAF (1993) Evolutionary origins and natural functions of fructans: a climatological, biogeographic and mechanistic appraisal. New Phytol 123:3-14

Hura K, Hura T, Dziurka K, Dziurka M (2014) Biochemical defense mechanisms induced in winter oilseed rape seedlings with different susceptibility to infection with Leptosphaeria maculans. Physiol Mol Plant Pathol 87:42-50

Janeczko A, Filek W (2002) Stimulation of generative development in partly vernalized winter wheat by animal sex hormones. Acta Physiol Plant 24:291-295

Janeczko A, Skoczowski A (2005) Mammalian sex hormones in plants. Folia Histochem Cyto 43:71-79

Janeczko A, Filek W, Biesaga-Kościelniak J, Marcińska I, Janeczko Z (2003) The influence of animal sex hormones on the induction of flowering in Arabidopsis thaliana: comparison with the effect of 24-epibrassinolide. Plant Cell Tissue Org Cult 72:147-151

Janeczko A, Biesaga-Kościelniak J, Oklestkova J, Filek M, Dziurka M, Szarek-Łukaszewska G, Kościelniak J (2010) Role of 24-Epibrassinolide in wheat production: physiological effects and uptake. J Agron Crop Sci 196:311-321

Janeczko A, Kocurek M, Marcińska I (2012) Mammalian androgen stimulates photosynthesis in drought-stressed soybean. Cent Eur J Biol 7:902-909

Janeczko A, Okleštková J, Siwek A, Dziurka M, Pociecha E, Kocurek M, Novák O (2013) Endogenous progesterone and its cellular binding sites in wheat exposed to drought stress. J Steroid Biochem 138:384-394

Janeczko A, Oklestkova J, Novak O, Śniegowska-Świerk K, Snaczke Z, Pociecha E (2015) Disturbances in production of progesterone and their implications in plant studies. Steroids 96:153-163

Kaplan F, Guy CL (2004) $\beta$-Amylase induction and the protective role of maltose during temperature shock. Plant Physiol 135:1674-1684

Kataoka K, Sumitomo K, Fudano T, Kawase K (2004) Changes in sugar content of Phalaenopsis leaves before floral transition. Sci Hortic 102:121-132

Khripach V, Zhabinskii V, De Groot A (2000) Twenty years of brassinosteroids: steroidal plant hormones warrant better crops for the XXI century. Ann Bot 86:441-447

King RW, Moritz T, Evans LT, Martin J, Andersen CH, Blundell C (2006) Regulation of flowering in the long-day grass Lolium temulentum by gibberellins and the FLOWERING LOCUS T gene. Plant Physiol 141:498-507

Kley HK, Deselaers T, Peerenboom H, Krüskemper HL (1980) Enhanced conversion of androstenedione to estrogens in obese males. J Clin Endocrinol Metab 51:1128-1132

Kovacs D, Kalmar E, Torok Z, Tompa P (2008) Chaperone activity of ERD10 and ERD14, two disordered stress-related plant proteins. Plant Physiol 147:381-390

Kulikowska-Gulewska H, Cymerski M, Czapiewska J, Koncewicz J (1995) IAA in the control of photoperiodic flower induction of Pharbitis nil chois. Acta Soc Bot Pol 64:45-50 
Laggner P, Filek M, Szechynska-Hebda M, Kriechbaum M (2003) $\mathrm{X}$-ray structure investigations of winter wheat membrane systems. II. Effect of phytohormones on structural properties of mixed phospholipid-sterols membranes. Plant Sci 165:271-275

Lang A (1952) Physiology of flowering. Ann Rev Plant Physiol 3:265-306

Livingston DP III, Henson CA (1998) Apoplastic sugars, fructans, fructan exohydrolase, and invertase in winter oat: responses to second-phase cold hardening. Plant Physiol 116:403-408

Los DA, Murata N (2004) Membrane fluidity and its roles in the perception of environmental signals. Biochim Biophys Acta 1666:142-157

Los DA, Mironov KS, Allakhverdiev SI (2013) Regulatory role of membrane fluidity in gene expression and physiological functions. Photosynth Res 116:489-509

Lück H (1962) Peroxidase. In: Bergmeyer HU (ed) Methoden der enzymatischen analyse 1962. Verlag Chemie, GmbH Weinheim, pp 895-897

McCord JM, Fiodovich I (1969) Superoxide dismutase an enzymic function for erythrocuprein (hemocuprein). J Biol Chem 244:6049-6055

Melchers G (1939) Die Blühormone. Ber Dtsch Bot GeS LVII:29-48

Milewich L, Whisenant MG (1982) Metabolism of androstenedione by human platelets: a source of potent androgens. J Clin Endocrinol Metab 54:969-974

Mok DWS, Mok MC (1994) Cytokinins: chemistry, activity, and function. CRC Press, Boca Raton

Müller J, Aeschbacher RA, Sprenger N, Boller T, Wiemken A (2000) Disaccharide mediated regulation of sucrose: fructan-6-fructosyltransferase, a key enzyme of fructan synthesis in barley leaves. Plant Physiol 123:265-274

Murashige T, Skoog F (1962) A revised medium for rapid growth and bioassays with plant tissue culture. Physiol Plant 15:473-497

Mutasa-Göttgens E, Hedden P (2009) Gibberellin as a factor in floral regulatory networks. J Exp Bot 60:1979-1989

Nishizawa-Yokoi A, Yabuta Y, Shigeoka SS (2008) The contribution of carbohydrates including raffinose family oligosaccharides and sugar alcohols to protection of plant cells from oxidative damage. Plant Signal Behav 3:1016-1018

Oslonovitch J, Li Y-J, Donner C, Krischer K (2003) The Fe(CN)63-/ $\mathrm{Fe}(\mathrm{CN}) 64$-charge transfer reaction on $\mathrm{Au}(111)$ revisited in the presence and absence of a two-dimensional, condensed organic film. J Electroanal Chem 541:163-174
Pociecha E, Dziurka M, Oklestkova J, Janeczko A (2016) Brassinosteroids increase winter survival of winter rye (Secale cereale L.) by affecting photosynthetic capacity and carbohydrate metabolism during the cold acclimation process. Plant Growth Regul 80:127-135

Rudolphi-Skórska E, Sieprawska A (2016) Physicochemical techniques in description of interactions in model and native plant membranes under stressful conditions and in physiological processes. Acta Physiol Plant 38:1-17

Rudolphi-Skórska E, Filek M, Zembala M (2014) Physicochemical aspects of reaction of ozone with galactolipid and galactolipidtocopherol layers. J Membr Biol 247:639-649

Sasaki H, Ichimura K, Oda M (1996) Changes in sugar content during cold acclimation and deacclimation of cabbage seedlings. Ann Bot 78:365-369

Scarth GW, Levitt J (1937) The frost-hardening mechanism of plant cells. Plant Physiol 12:51-78

Senaratna T, Merritt D, Dixon K, Bunn E, Touchell D, Sivasithamparam K (2003) Benzoic acid may act as the functional group in salicylic acid and derivatives in the induction of multiple stress tolerance in plants. Plant Growth Regul 39:77-81

Sharma M, Laxmi A (2015) Jasmonates: emerging players in controlling temperature stress tolerance. Front Plant Sci 6:1129

Silverstone AL, Chang C-W, Krol E, Sun T-P (1997) Developmental regulation of the gibberellin biosynthetic gene GA1 in Arabidopsis thaliana. Plant J 12:9-19

Simerský R, Novak O, Morris DA, Pouzar V, Strnad M (2009) Identification and quantification of several mammalian steroid hormones in plants by UPLC-MS/MS. J Plant Growth Regul 28:125-136

Skoczowski A, Filek M (1994) Changes in fatty acids composition of subcellular fractions from hypocotyls of winter rape growing at $2{ }^{\circ} \mathrm{C}$ or $20^{\circ} \mathrm{C}$. Plant Sci $98: 127-133$

Tarkowska D, Filek M, Biesaga-Koscielniak J, Marcinska I, Machackova I, Krekule J, Strnad M (2012) Cytokinins in shoot apices of Brassica napus plants during vernalization. Plant Sci 187:105-112

Werner T, Motyka V, Laucou V, Smets R, Van Onckelen H, Schmülling T (2003) Cytokinin-deficient transgenic Arabidopsis plants show multiple developmental alterations indicating opposite functions of cytokinins in the regulation of shoot and root meristem activity. Plant Cell 15:2532-2550 